\title{
FTY720, a new alternative for treating blast crisis chronic myelogenous leukemia and Philadelphia chromosome-positive acute lymphocytic leukemia
}

\author{
Paolo Neviani, ${ }^{1}$ Ramasamy Santhanam, ${ }^{1}$ Joshua J. Oaks, ${ }^{1}$ Anna M. Eiring, ${ }^{1}$ Mario Notari, 1
}

Bradley W. Blaser, ${ }^{2}$ Shujun Liu, ${ }^{2}$ Rossana Trotta, ${ }^{1}$ Natarajan Muthusamy, ${ }^{2}$

Carlo Gambacorti-Passerini, ${ }^{3}$ Brian J. Druker, ${ }^{4}$ Jorge Cortes, ${ }^{5}$ Guido Marcucci, 1,2,6

Ching-Shih Chen, ${ }^{6,7,8}$ Nicole M. Verrills, ${ }^{9}$ Denis C. Roy, ${ }^{10}$ Michael A. Caligiuri, ${ }^{1,2,6}$

Clara D. Bloomfield, ${ }^{6}$ John C. Byrd,1,2,6 and Danilo Perrotti1,6

\begin{abstract}
1Human Cancer Genetics Program, Department of Molecular Virology, Immunology and Medical Genetics, and
2Division of Hematology/Oncology, Department of Internal Medicine, The Ohio State University, Columbus, Ohio, USA.

${ }^{3}$ University of Milano Bicocca, S. Gerardo Hospital, Monza, Italy. ${ }^{4}$ Department of Hematology and Oncology,

Oregon Health and Science University Cancer Institute, Portland, Oregon, USA. 5Leukemia Department, University of Texas MD Anderson Cancer Center, Houston, Texas, USA. ${ }^{6}$ The Ohio State University Comprehensive Cancer Center, Columbus, Ohio, USA. ${ }^{7}$ Division of Medicinal Chemistry,

College of Pharmacy, and ${ }^{8} \mathrm{College}$ of Veterinary Bioscience, The Ohio State University, Columbus, Ohio, USA. ${ }^{9}$ School of Biomedical Sciences and Hunter Medical Research Institute, Faculty of Health, University of Newcastle, Callaghan, New South Wales, Australia. ${ }^{10}$ Division of Hematology-Immunology, Maisonneuve-Rosemont Hospital Research Center, Department of Medicine, Université de Montréal, Montreal, Quebec, Canada.
\end{abstract}

\begin{abstract}
Blast crisis chronic myelogenous leukemia (CML-BC) and Philadelphia chromosome-positive (Ph1-positive) acute lymphocytic leukemia (ALL) are 2 fatal BCR/ABL-driven leukemias against which Abl kinase inhibitors fail to induce a long-term response. We recently reported that functional loss of protein phosphatase 2A (PP2A) activity is important for CML blastic transformation. We assessed the therapeutic potential of the PP2A activator FTY720 (2-amino-2-[2-(4-octylphenyl)ethyl]-1,3-propanediol hydrochloride), an immunomodulator in Phase III trials for patients with multiple sclerosis or undergoing organ transplantation, in CML-BC and Ph1 ALL patient cells and in in vitro and in vivo models of these $B C R / A B L^{+}$leukemias. Our data indicate that FTY720 induces apoptosis and impairs clonogenicity of imatinib/dasatinib-sensitive and -resistant p210/ $\mathrm{p} 190^{\mathrm{BCR} / \mathrm{ABL}}$ myeloid and lymphoid cell lines and $\mathrm{CML}-\mathrm{BC}^{\mathrm{CD} 34+}$ and $\mathrm{Ph} 1 \mathrm{ALL}^{\mathrm{CD} 34+/ \mathrm{CD}^{39+}}$ progenitors but not of normal CD34 ${ }^{+}$and $\mathrm{CD} 34^{+} / \mathrm{CD}^{+} 9^{+}$bone marrow cells. Furthermore, pharmacologic doses of FTY720 remarkably suppress in vivo $\mathrm{p} 210 / \mathrm{p}^{190^{\mathrm{BCR}} / \mathrm{ABL}}$-driven [including $\mathrm{p} 210 / \mathrm{p} 190^{\mathrm{BCR} / \mathrm{ABL}}(\mathrm{T} 315 \mathrm{I})$ ] leukemogenesis without exerting any toxicity. Altogether, these results highlight the therapeutic relevance of rescuing PP2A tumor suppressor activity in Ph1 leukemias and strongly support the introduction of the PP2A activator FTY720 in the treatment of CML-BC and Ph1 ALL patients.
\end{abstract}

\section{Introduction}

The $B C R-A B L 1$ oncogene, product of the Philadelphia chromosome $(\mathrm{Ph} 1)$ translocation $\mathrm{t}(9 ; 22)(\mathrm{q} 34 ; \mathrm{q} 11)$, is the hallmark of chronic myelogenous leukemia (CML) (1) and a poor prognostic factor in at least $20 \%$ of adult acute lymphoblastic leukemias (ALL) (2). The BCR-ABL1-encoded isoform p210 is detected in almost all CML patients, whereas $\mathrm{p} 190$ is found in most Ph1 ALL patients (3). p190 appears to have higher tyrosine kinase activity than p210

Nonstandard abbreviations used: ALL, acute lymphocytic leukemia; BC, blast crisis; $\mathrm{CML}$, chronic myelogenous leukemia; $\mathrm{CP}$, chronic phase; DMS, $N$, $N$-dimethylsphingosine; $\mathrm{EC}_{50}, 50 \%$ effective concentration; FTY720-P, phosphorylated FTY720; NBM, normal bone marrow; $\mathrm{PB}$, peripheral blood; Ph1, Philadelphia chromosome; PP2A, protein phosphatase 2A; PP2A , PP2A structural/regulatory subunit A; PP2 $\mathrm{A}_{\mathrm{AC}}$, PP2A dimer containing the A and C subunits; PP2Ac, PP2A catalytic subunit; PTX, pertussis toxin; S1P, sphingosine-1-phosphate; S1PR, S1P receptor; SPHK, sphingosine kinase; small-t, SV40 small T antigen.

Conflict of interest: D. Perrotti, P. Neviani, R. Santhanam, J.C. Byrd, G. Marcucci, N. Muthusamy, and C.-S. Chen have a patent pending for the use of PP2A-activating drugs for the treatment of $\mathrm{Ph} 1$ leukemias. All other authors have declared that no conflict of interest exists.

Citation for this article: J. Clin. Invest. 117:2408-2421 (2007). doi:10.1172/JCI31095. but similar transforming ability and preferential expression in lymphoid progenitors, where it potently stimulates proliferation (4). By contrast, p210 expression is primarily restricted to the myeloid compartment, where it induces CML (5), a myeloproliferative disorder that depends on increased survival rather than enhanced proliferation of myeloid progenitors (6).

The natural history of CML is characterized by the progression from an indolent chronic phase (CP) to an aggressive myeloid or lymphoid blast crisis (BC) phase (7), a disease stage biologically similar to acute leukemia (8). Moreover, CML is a pluripotent hematopoietic stem cell disease, whereas the origin of Ph1 ALL is still controversial $(9,10)$, though there is evidence suggesting that it may arise from neoplastic transformation of a B cell-committed progenitor $(9,11)$. Nevertheless, although they are clinically distinct, CML (CP and $\mathrm{BC}$ ) and Ph1 ALL are progenitor-driven leukemias (11) whose emergence and maintenance are dependent on the unrestrained kinase activity of $\mathrm{BCR} / \mathrm{ABL}$ oncoproteins $(8,12)$. These recruit and activate multiple pathways that transduce oncogenic signals, leading to increased survival, enhanced proliferation, and arrested differentiation of hematopoietic progenitors $(13,14)$. 
A
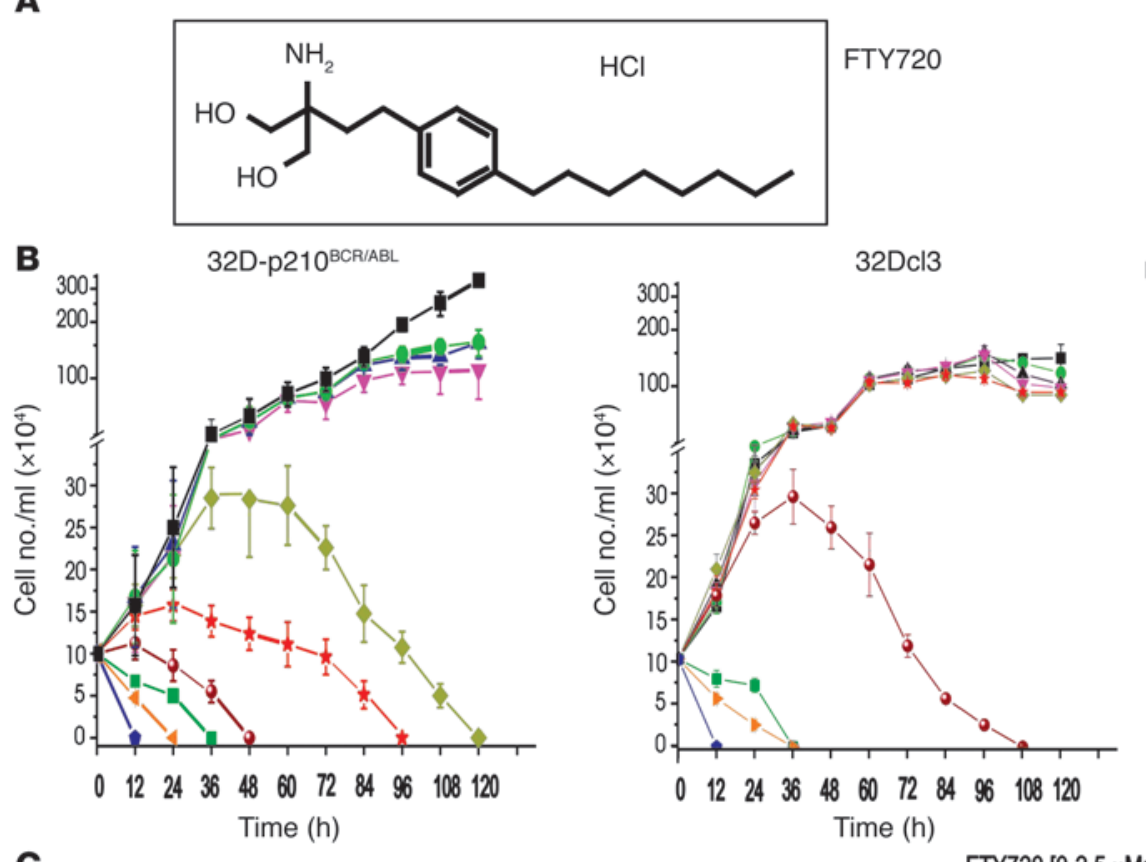

FTY720 doses
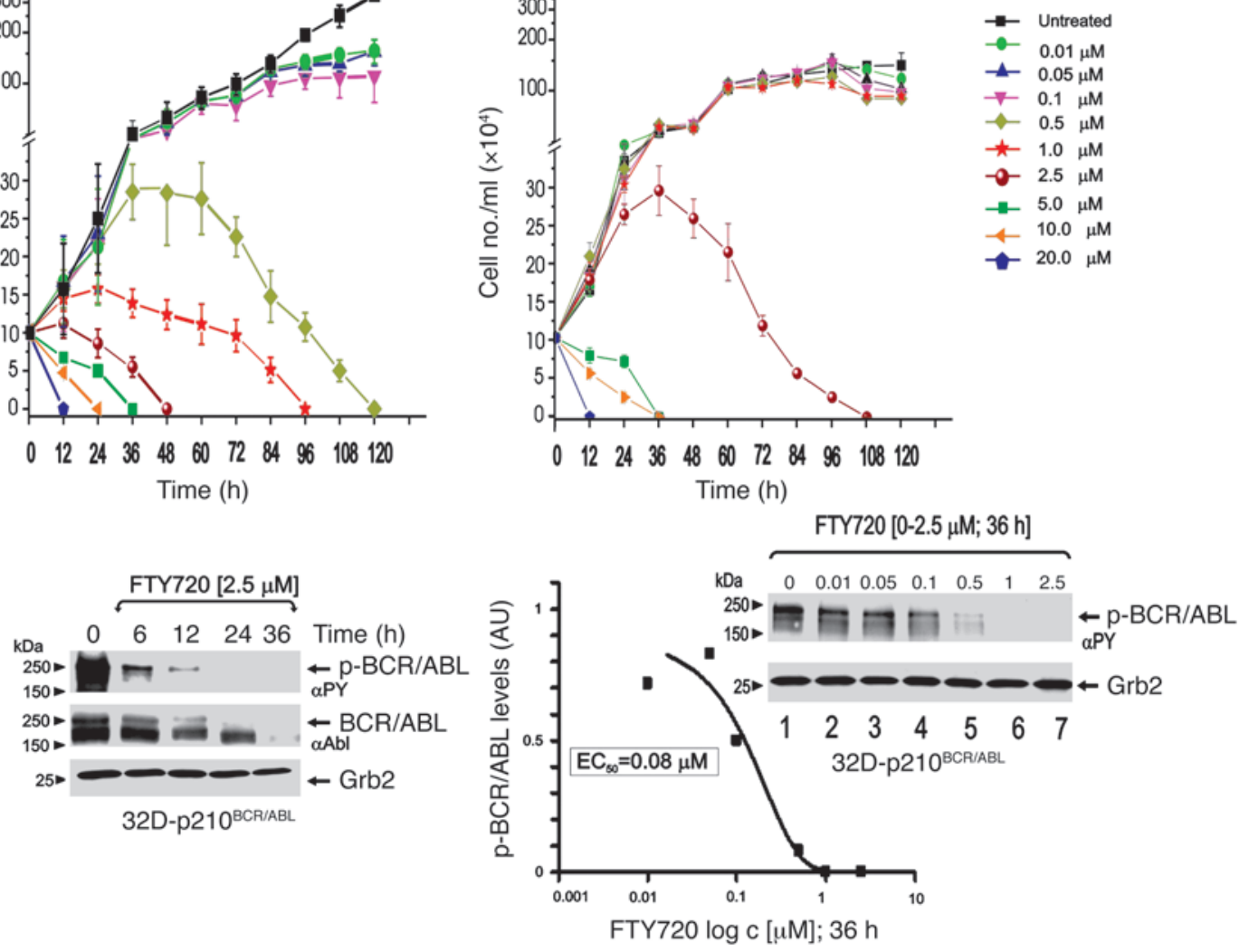

Figure 1

Dose-dependent effects of FTY720 in BCR/ABL-transformed cells. (A) Molecular structure of FTY720 (2-amino-2-[2-(4-octylphenyl)ethyl]-1,3propanediol hydrochloride). (B) Effect of different doses $(0-20 \mu \mathrm{M})$ of FTY720 on cytokine-independent proliferation of 32D-p210BCR/ABL cells and IL-3-dependent proliferation of parental 32Dcl3 cells. (C) p210BCR/ABL tyrosine phosphorylation ( $\alpha$ PY) and expression ( $\alpha$ Abl) in 32D-p210BCR/ABL cells untreated and treated 6-36 hours with $2.5 \mu \mathrm{M}$ FTY720 (left panel). Graph shows levels of phosphorylated BCR/ABL (expressed as arbitrary densitometric units normalized to Grb2 levels) in 32D-p210 BCR/ABL cells treated for 36 hours with the indicated concentrations of FTY720. Right blot: p210 $\mathrm{BCR} / \mathrm{ABL}$ activity in 32D-p210 $\mathrm{BCR} / \mathrm{ABL}$ cells treated for 36 hours with FTY720 $(0-2.5 \mu \mathrm{M})$.

The BCR/ABL kinase inhibitor imatinib mesylate (15) has remarkable therapeutic efficacy in CML-CP $(16,17)$. By contrast, most of the Ph1 ALL and CML-BC patients are refractory or develop resistance to imatinib monotherapy $(16,18-20)$. In these patients, resistance often depends on mechanisms involving $\mathrm{BCR} / \mathrm{ABL}$ overexpression or mutations (21). Recently, the $\mathrm{Src} / \mathrm{Abl}$ inhibitor dasatinib and the Abl inhibitor nilotinib have shown encouraging results in imatinib-resistant CML-CP patients $(22,23)$, as they suppress the activity of most BCR/ABL mutants (other than T315I) (24). However, in vitro evidence suggests that resistance to these compounds may develop through selection/expansion of $\mathrm{BCR} / \mathrm{ABL}^{+}$cell clones carrying the $\mathrm{T} 315 \mathrm{I}$ mutation (25). In addition, dasatinib and nilotinib are not effective in CML-BC or Ph1 ALL, as patients either do not respond or relapse after a few months of therapy $(22,23)$. Thus it is possible that successful treatment of CML-BC and Ph1 ALL may require alternative strategies that simultaneously target BCR/ABL and its signalosome through mechanisms different from those utilized by traditional kinase inhibitors.

We recently reported that $\mathrm{p} 210-\mathrm{BCR} / \mathrm{ABL}$ inactivates the tumor suppressor PP2A by enhancing the expression of the PP2A inhibitor SET and that PP2A loss-of-function accounts for increased and sustained BCR/ABL activity in CML-BC progenitors (26). In fact, reactivation of $\mathrm{PP} 2 \mathrm{~A}$ activity impairs BCR/ABL expression and function, leading to growth suppression, enhanced apoptosis, impaired clonogenicity, and decreased in vivo leukemogenesis of imatinib-sensitive and -resistant $\mathrm{BCR} / \mathrm{ABL}^{+}$lines and myeloid CML-BC patient cells (26).

In this study we assessed the therapeutic potential of the PP2A activator (27) FTY720 (also known as fingolimod) in CML-BC and Ph1 ALL progenitors and in models of in vitro and in vivo p210 and p190 BCR/ABL leukemogenesis. FTY720, a synthetic myriocin 

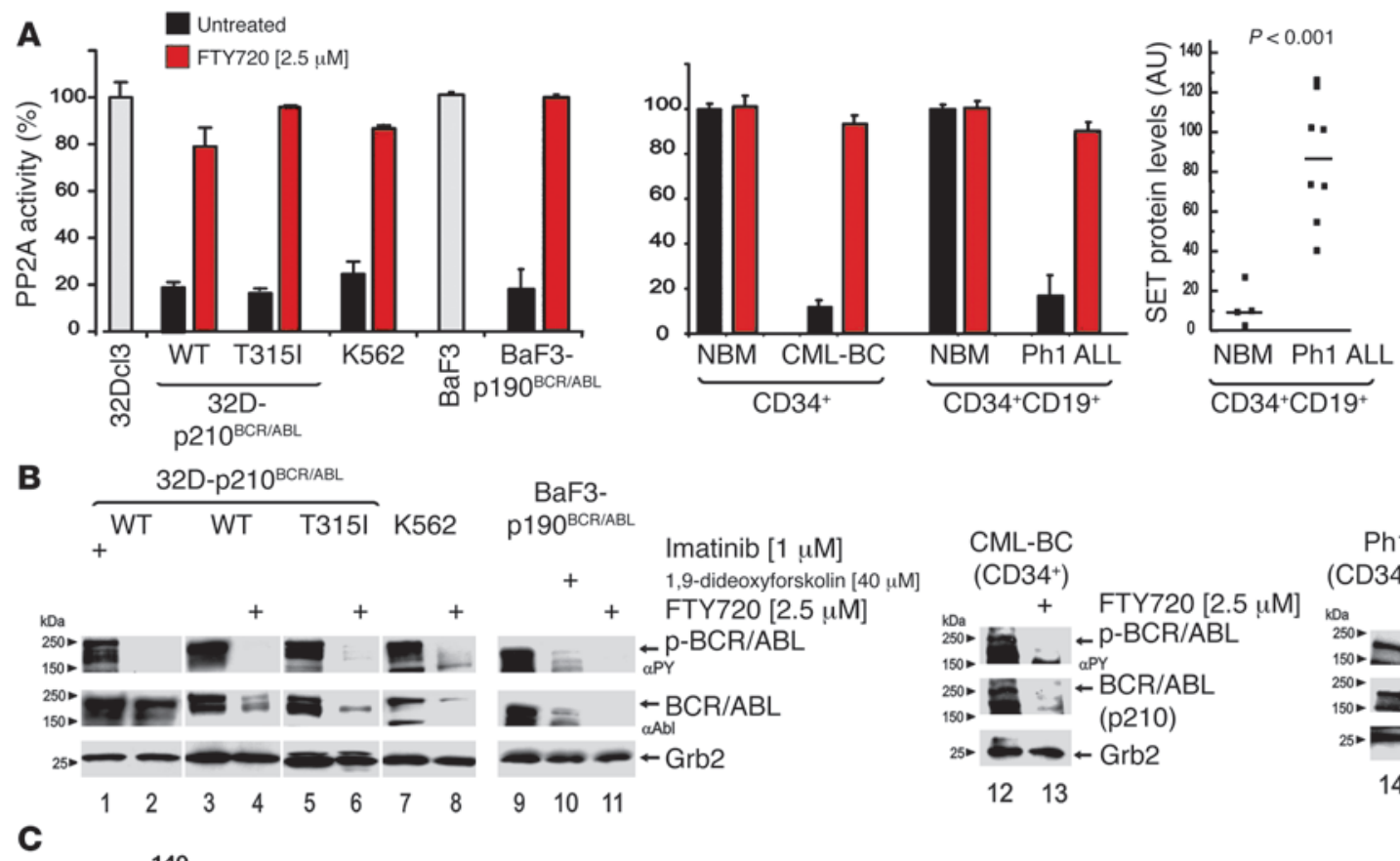

$\mathrm{Ph} 1 \mathrm{ALL}$ $\left(\mathrm{CD} 34^{+} \mathrm{CD} 19^{+}\right)$
+ FTY720 $[2.5 \mu \mathrm{M}]$
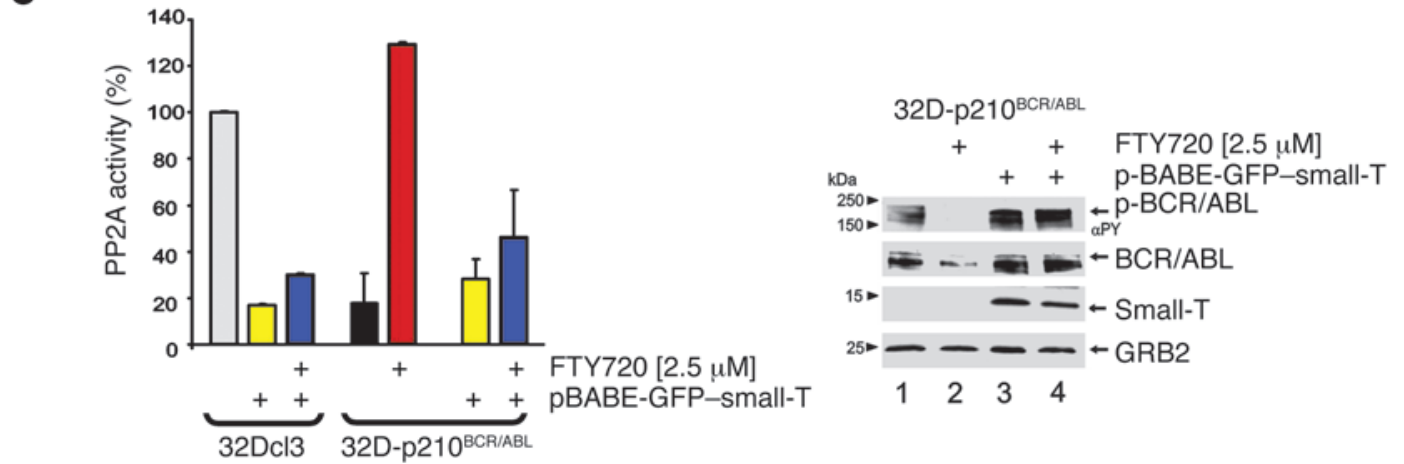

Figure 2

FTY720-dependent activation of PP2A and suppression of p210 and p190 BCR/ABL in myeloid and lymphoid cell lines and in CML-BC and Ph1 ALL patient cells. (A) PP2A assay in untreated (black bars) and FTY720-treated (red bars) 32D-p210BCR/ABL (wild-type and T315I), K562, BaF3-p190 BCR/ABL, CML-BCCD34+ $(n=11)$, and Ph1 ALLCD34+/CD19+ $(n=12)$; PP2A activity in untreated and FTY720-treated BCR/ABL ${ }^{+}$cell lines and primary patient cells is expressed as percentage of the PP2A activity in untreated 32Dcl3 or BaF3 (white bars) and in NBMCD34+ $(n=4)$ and $\mathrm{NBMCD} 34+\mathrm{CD} 19+(n=4)$ cells, respectively. Dot plot shows SET protein levels expressed as arbitrary densitometric units normalized to Grb2 protein levels in NBMCD34+/CD19+ $(n=4)$ and Ph1 ALLCD34+/CD19+ cells $(n=12)\left(P<0.001\right.$, Student $t$-test). (B) p210 ${ }^{\mathrm{BCR} / \mathrm{ABL}}$ and p190 ${ }^{\mathrm{BCR} / \mathrm{ABL}}$ activity and expression in untreated and FTY720-, imatinib-, and 1,9-dideoxyforskolin-treated 32D-p210 BCR/ABL (wild-type and T315I), K562, BaF3-p190BCR/ABL, $\mathrm{CML}-\mathrm{BC}^{\mathrm{CD} 34+}(n=3)$, and Ph1 ALLCD34+/CD19+ cells $(n=6)$. Grb2 protein levels were detected as control for equal loading. (C) Left: PP2A assay in untreated pBABE-GFP vector-transduced 32Dcl3 (white bar) and 32D-p210BCR/ABL (black bar) cells, small-t-expressing 32Dcl3 and 32Dp210BCR/ABL cells (yellow bars), FTY720-treated 32D-p210BCR/ABL (red bars) and in FTY720-treated small-t-expressing (pBabe-GFP-small-T) 32Dcl3 and 32D-p210 BCR/ABL cells (blue bars). Right: Western blots show effect of small-t expression on BCR/ABL activity and expression in untreated and FTY720-treated 32D-p210 BCR/ABL cells.

analog structurally similar to sphingosine, is a water-soluble, nontoxic drug with high oral bioavailability that reversibly arrests lymphocyte trafficking (mainly of $\mathrm{CD}^{+} \mathrm{T}$ cells) (28-31). It is currently used as an immunomodulator in Phase III trials for patients with multiple sclerosis or undergoing renal transplantation (32-35).

Here we present data supporting the investigation of FTY720 as a novel therapeutic approach for patients with imatinib/dasatinibsensitive and -resistant advanced CML and Ph1 ALL. We show that FTY720 is a potent inhibitor of BCR/ABL leukemogenesis, as it induces marked apoptosis of CML-BC ${ }^{\mathrm{CD} 34+}$ and $\mathrm{Ph} 1 \mathrm{ALL}^{\mathrm{CD} 34+/ \mathrm{CD} 19+}$ patient cells by impairing p210/p190-BCR/ABL activity and expression via activation of PP2A. Furthermore, in vivo long-term administration of pharmacologic FTY720 doses (36) does not induce adverse effects and significantly inhibits wild-type and T315I p210 and p190 BCR/ABL leukemogenesis in mice.

\section{Results}

FTY720 suppresses growth of BCR/ABL-transformed myeloid and lymphoid cells in a dose-dependent manner. The dose-dependent effect of FTY720 (Figure 1A) on BCR/ABL-dependent cell proliferation and $\mathrm{BCR} / \mathrm{ABL}$ activity was initially assessed in $\mathrm{p} 210^{\mathrm{BCR} / \mathrm{ABL}}$-transformed myeloid precursor 32Dcl3 cells (32D-p210 ${ }^{\mathrm{BCR} / \mathrm{ABL}}$ cells). Treatment 

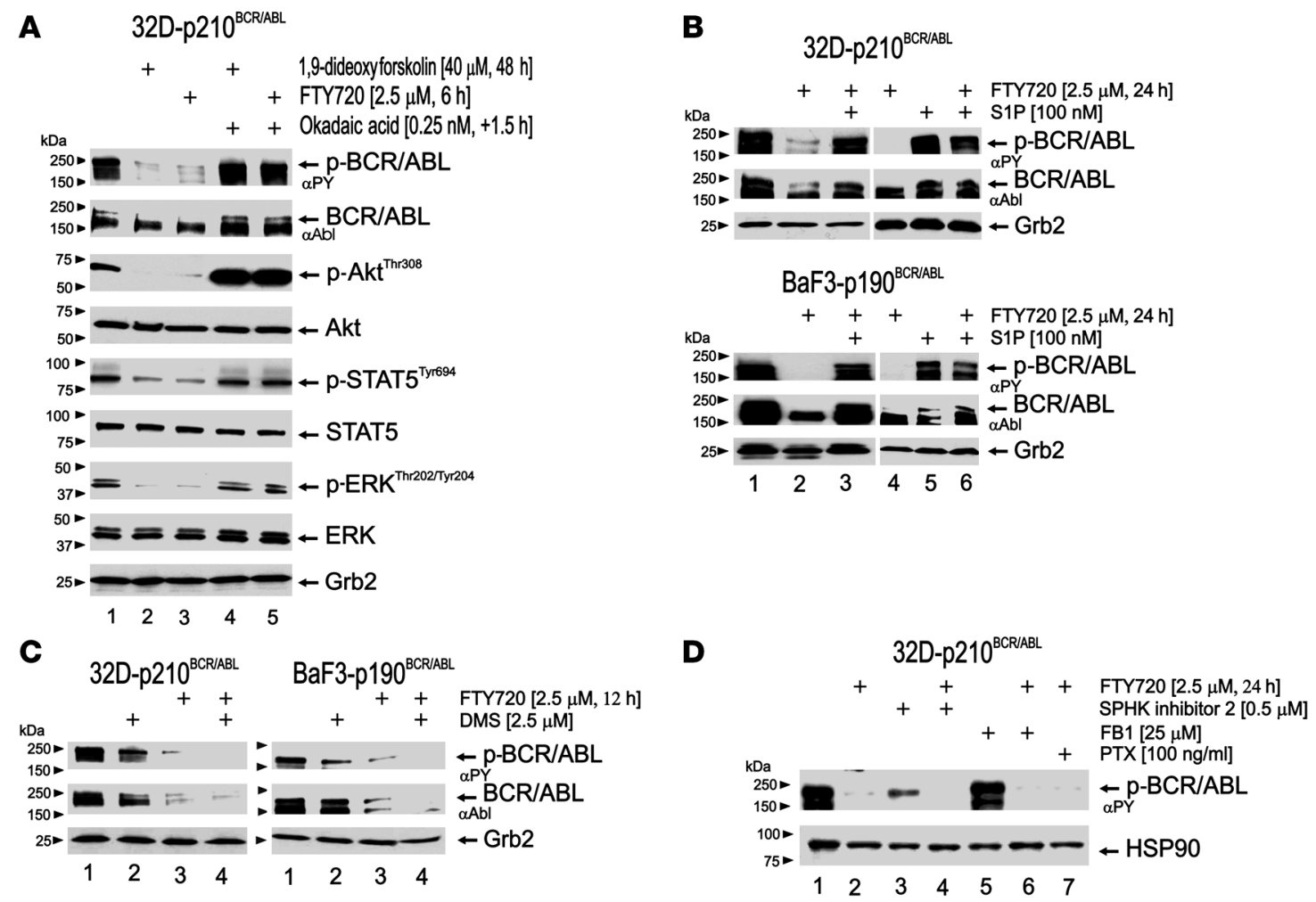

\section{Figure 3}

FTY720-induced inactivation of BCR/ABL, Akt, STAT5, and ERK is PP2A mediated and does not require FTY720 phosphorylation. (A) Effect of

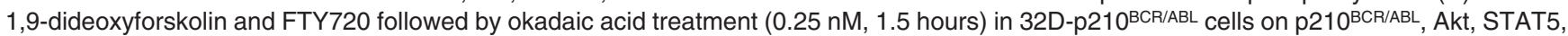
and ERK1/2 activity and expression. (B) Western blots show the effect of S1P alone or in combination with FTY720 (100 nM S1P, 1 hour treatment before exposure to FTY720) on FTY720-induced p210 BCR/ABL and p190BCR/ABL inactivation and downregulation. (C) Effect of SPHK inhibitor DMS $\left(2.5 \mu \mathrm{M}\right.$; 30-minute pretreatment) on FTY720-induced $\mathrm{p} 210^{\mathrm{BCR} / \mathrm{ABL}}$ and $\mathrm{p} 190^{\mathrm{BCR} / \mathrm{ABL}}$ inactivation and downregulation. GRB2 protein levels were used as loading control. (D) Effect of SPHK inhibitor $2(0.5 \mu \mathrm{M})$, fumonisin B1 (FB1; $25 \mu \mathrm{M})$, and PTX (100 ng/ml) on FTY720-induced $\mathrm{BCR} / \mathrm{ABL}$ dephosphorylation. PTX was given to the cells 16 hours before exposure to FTY720, and FB1 and SPHK inhibitor 2 were administered 1 hour before exposure to FTY720. HSP90 levels were detected as control for equal loading.

with increasing concentrations of FTY720 $(0.01-20 \mu \mathrm{M})$ for 0 to 120 hours led to dose-dependent growth inhibition followed by cell death (Figure 1B). Specifically, FTY720 at 2.5 and $0.5 \mu \mathrm{M}$ induced cell death within 48 and 120 hours, respectively. At lower concentrations (0.01 to $0.1 \mu \mathrm{M})$, FTY720 markedly suppressed proliferation (50\%-75\% growth inhibition) without impairing cell viability (Figure 1B). Similar dose-dependent growth-inhibition was observed in FTY720-treated lymphoid BaF3 progenitor cells transformed with $\mathrm{p} 190^{\mathrm{BCR} / \mathrm{ABL}}$ (data not shown). By contrast, IL-3-dependent proliferation of nontransformed 32Dcl3 myeloid precursors was not affected by concentrations of FTY720 ranging from 0.01 to $1 \mu \mathrm{M}$ (Figure $1 \mathrm{~B}$ ). Moreover, 32 Dcl3 cells exposed to $2.5 \mu \mathrm{M}$ FTY720 continued to grow and were all alive after 36-48 hours of treatment and thereafter slowly underwent apoptosis (Figure 1B). Notably, continued exposure to $2.5 \mu \mathrm{M}$ FTY720 induced death of 32D-BCR/ABL and parental 32Dcl3 cells within 48 and 108 hours, respectively (Figure 1B), suggesting that BCR/ ABL-expressing cells are much more sensitive to FTY720 than are nontransformed cells. Interestingly, the increased FTY720 sensitivity of $\mathrm{BCR} / \mathrm{ABL}^{+}$cells depends on the ability of this drug to induce $\mathrm{BCR} / \mathrm{ABL}$ dephosphorylation (inactivation) and downregulation (Figure 1C). In fact, levels of tyrosine-phosphorylated (active) p $210^{\mathrm{BCR} / \mathrm{ABL}}$ were dramatically reduced within 6 hours, barely detectable at 12 hours, and absent at 24 hours of treatment with $2.5 \mu$ M FTY720 (Figure 1C). Similarly, BCR/ABL expression was downregulated by $2.5 \mu \mathrm{M}$ FTY720, although this occurred at later time points than dephosphorylation (Figure 1C). Note that 32D$\mathrm{p} 210^{\mathrm{BCR} / \mathrm{ABL}}$ cell viability was not affected after 12 hours and partially decreased (25\% reduction) after 24 hours of treatment with $2.5 \mu \mathrm{M}$ FTY720, indicating that inhibition of BCR/ABL precedes, and most likely accounts for, FTY720-induced cell death. Further supporting this is the gradual inhibition of BCR/ABL activity observed when cells were treated with FTY720 at concentrations of 0.01 to $0.5 \mu \mathrm{M}$ (Figure 1C), which impaired proliferation but did not induce cell death (Figure 1B). Indeed, FTY720 treatment (at 36 hours) suppressed BCR/ABL activity with an 50\% effective concentration $\left(\mathrm{EC}_{50}\right)$ of approximately $80 \mathrm{nM}$ (Figure $1 \mathrm{C}$ ).

FTY720 restores the activity of the PP2A tumor suppressor and hampers that of 210 and $p 190$ BCR/ABL oncoproteins in CML-BC and Ph1 ALL cells. Phosphatase assays were performed using PP2A catalytic subunit (PP2Ac) immunoprecipitates from myeloid 32Dcl3 and proB lymphoid BaF3 precursors as controls, untreated and FTY720treated ( $2.5 \mu \mathrm{M} ; 6$ hours) imatinib-sensitive and -resistant (T315I)

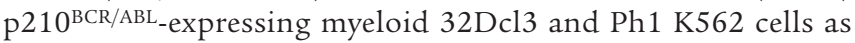
models of CML-BC; and untreated and FTY720-treated $(2.5 \mu \mathrm{M}$;

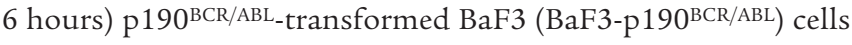


A

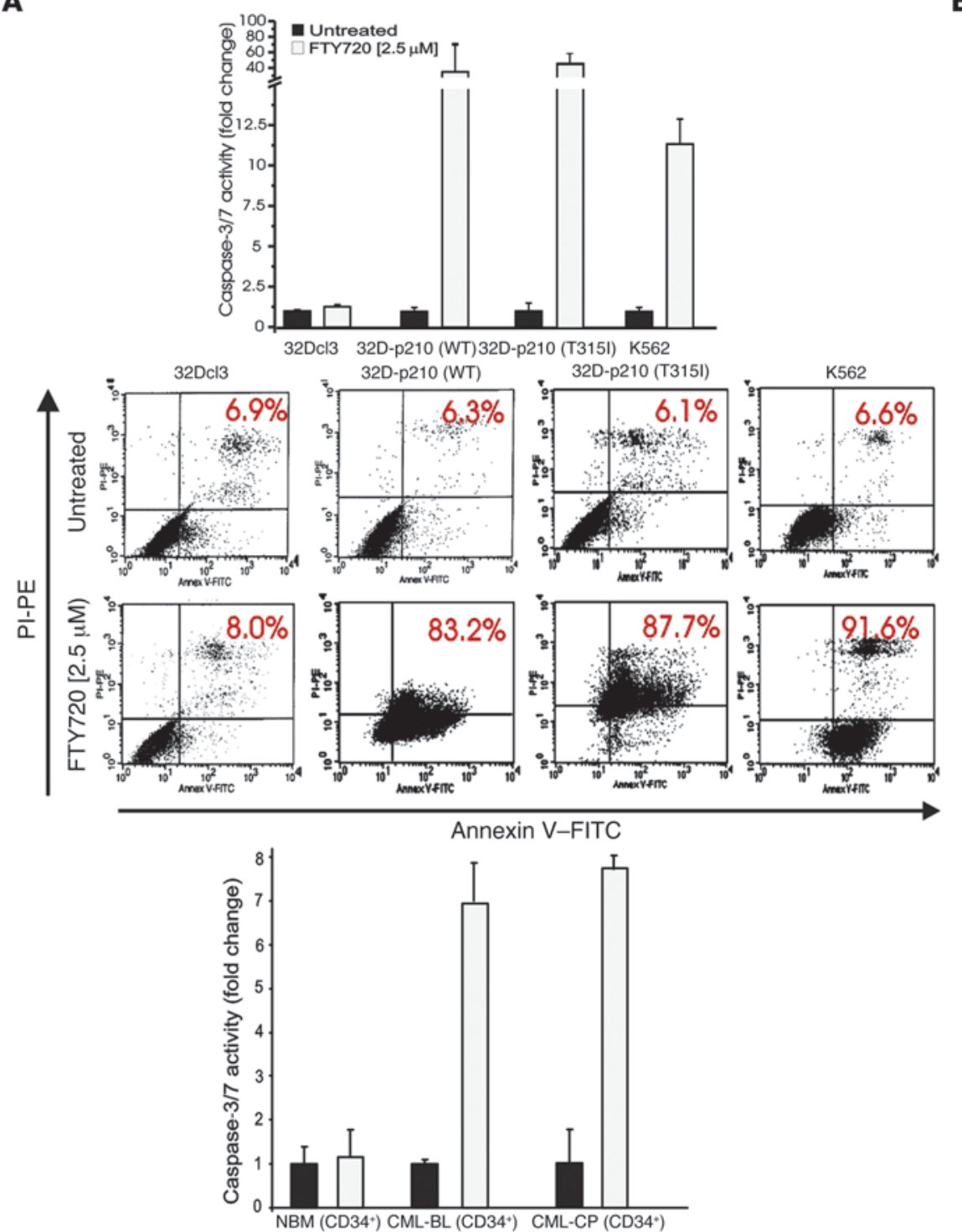

B
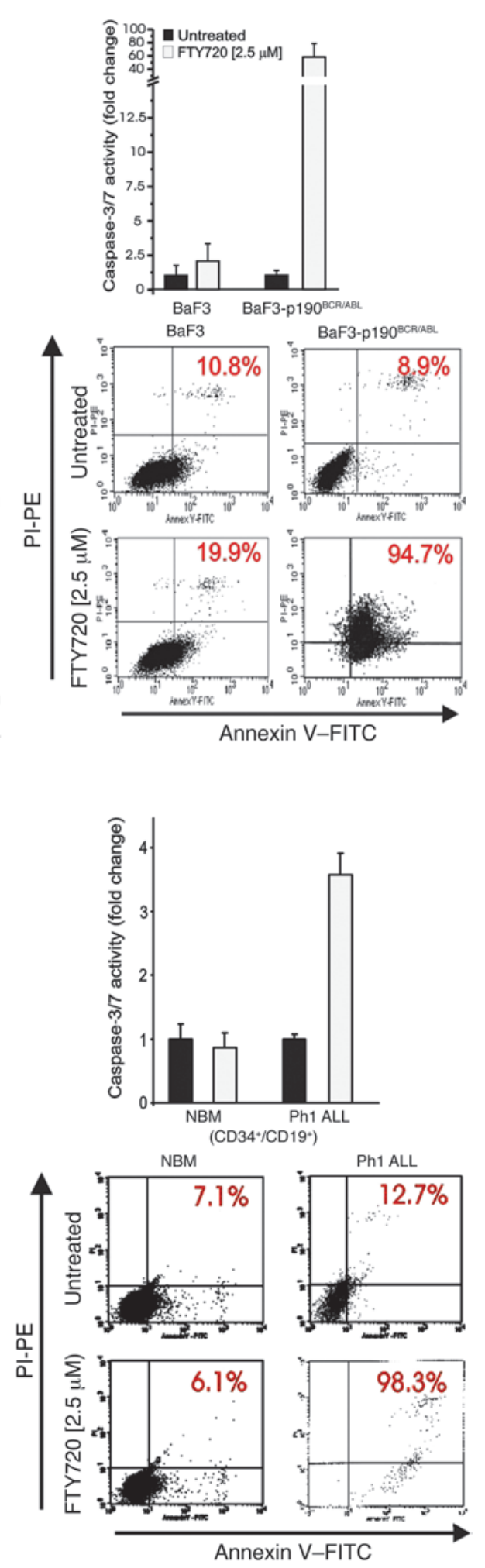

Figure 4

FTY720 induces caspase-dependent apoptosis of primary Ph1 leukemia progenitors and imatinib-sensitive and T315I BCR/ABL+ myeloid and/or lymphoid lines. Caspase-3/7 (graphs) and annexin-V/propidium iodide (annexin-V/PI) (flow cytometry dot plots) assays in untreated and FTY720treated $(2.5 \mu \mathrm{M})(\mathbf{A})$ myeloid 32Dcl3, 32D-p210BCR/ABL (wild-type and T315I), K562, NBMCD34+ $(n=3)$, CML-CPCD34+ $(n=3)$, and CML-BCCD34+ $(n=3)$ and $(\mathbf{B})$ lymphoid BaF3, BaF3-p190BCR/ABL, NBMCD34+/CD19+ $(n=3)$, and Ph1 ALLCD34+/CD19+ $(n=3)$ cells. 

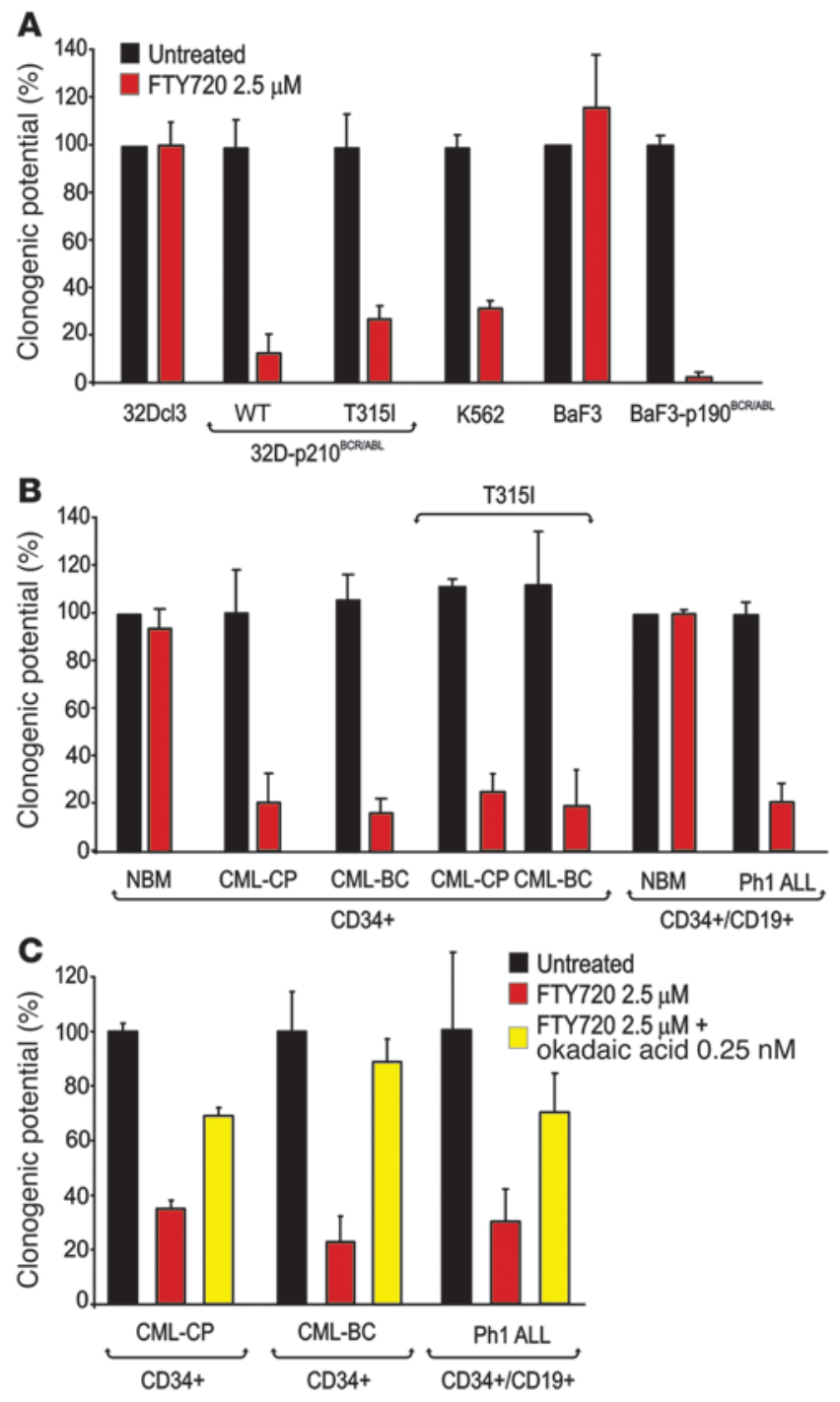

as models of Ph1 ALL. As expected, PP2A activity was markedly reduced by $80 \%$ or more in wild-type and $\mathrm{T} 315 \mathrm{I} \mathrm{p} 210^{\mathrm{BCR} / \mathrm{ABL}}$-expressing cell lines compared with parental 32Dcl3 cells (Figure 2A). Likewise, untreated BaF3-p190 ${ }^{\mathrm{BCR} / \mathrm{ABL}}$ cells exhibited low levels of PP2A activity corresponding to $20 \%-25 \%$ of those measured in parental BaF3 cells (Figure 2A). Importantly, FTY720 treatment of 32D-p210 ${ }^{\mathrm{BCR} / \mathrm{ABL}}$ and $\mathrm{BaF} 3-\mathrm{p} 190^{\mathrm{BCR} / \mathrm{ABL}}$ cells restored PP2A activity to levels similar to those of parental cells (Figure 2A).

PP2A activity was also reduced by $90 \%$ in myeloid CML-BC ${ }^{\mathrm{CD} 34+}$ $(n=11)$ compared to the $\mathrm{CD} 34^{+}$fraction from normal bone marrow (NBM) donors, and reduced by $82 \%$ in $\mathrm{Ph} 1 \mathrm{ALL}^{\mathrm{CD} 34+/ \mathrm{CD} 19+}(n=12)$ compared to the $\mathrm{CD} 34^{+} / \mathrm{CD} 19^{+}$fraction from NBM donors $(n=8)$ (Figure 2A). Consistently, treatment of CML-BCCD34+ and $\mathrm{Ph} 1$ $\mathrm{ALL}^{\mathrm{CD} 34+/ \mathrm{CD} 19+}$ progenitors with FTY720 $(2.5 \mu \mathrm{M}$; 48 hours $)$ in the presence of myeloid or lymphoid cytokines reestablished PP2A activity to levels observed in normal CD34 ${ }^{+}$myeloid and $\mathrm{CD} 34^{+} /$ $\mathrm{CD}_{19}{ }^{+}$lymphoid progenitors (Figure 2A). By contrast, FTY720 did not overinduce PP2A activity in primary NBM progenitors (Figure 2A). Notably, the presence of cytokines in primary CML-BC and $\mathrm{Ph} 1 \mathrm{ALL}$ cultures, but not in growth factor-independent cell lines, may account for differences in the kinetics of PP2A activation.

\section{Figure 5}

In vitro antileukemic effects of FTY720 in imatinib-sensitive and -resistant (T315I) Ph1 leukemia marrow progenitors and BCR/ABL + cell lines. (A) Growth factor-independent methylcellulose colony formation (expressed as mean \pm SD of percentage of clonogenic potential from 3 experiments) of untreated and FTY720-treated 32D-p210BCR/ABL (WT and T315I), BaF3-p190BCR/ABL, and K562 cells. As control, 100\% clonogenic potential was attributed to the IL-3-dependent colony-forming ability of untreated and FTY720-treated parental 32Dcl3 and BaF3 cells. (B) IL-3- (for myeloid progenitors) and IL-7-dependent (for lymphoid progenitors) colony-forming ability (expressed as mean \pm SD of percentage of clonogenic potential from 3 assays performed with each patient sample) of untreated (dark bars) and FTY720-treated NBMCD34+ $(n=4)$, CML-CPCD34+ $(n=3)$, CML-BCCD34+ $(n=11)$, CML-CPCD34+ (T315I) $(n=1), \mathrm{CML}-\mathrm{BC}^{\mathrm{CD} 34+}(\mathrm{T} 315 \mathrm{I})(n=3), \mathrm{NBM}^{\mathrm{CD} 34+/ \mathrm{CD} 19+}(n=4)$, and Ph1 ALLCD34+/CD19+ $(n=12)$ cells. As controls, $100 \%$ clonogenic potential was attributed to the IL-3- and IL-7-driven colony formation of NBM ${ }^{\mathrm{CD} 34+}$ and $\mathrm{NBM}^{\mathrm{CD} 34+/ \mathrm{CD} 19+}$, respectively. (C) Inhibition of PP2A activity by okadaic acid $(0.25 \mathrm{nM})$ rescues the clonogenic potential (expressed as mean \pm SD of percentage of conogenic potential from 3 independent assays performed with each patient sample) of FTY720treated CML-CPCD34+, CML-BCCD34+, and Ph1 ALLCD34+/CD19+ cells.

Indeed, we previously reported that expression of the PP2A inhibitor SET (37) increases upon cytokine stimulation of NBM CD34 ${ }^{+}$progenitors $(26)$.

As in myeloid CML-BC (26), suppression of PP2A activity in $\mathrm{Ph} 1 \mathrm{ALL}$ is also dependent on enhanced expression of the BCR/ ABL-regulated (26) SET. In fact, SET protein levels were significantly $(P<0.001$; Student's $t$ test) higher in Ph1 ALLCD34+/CD19+ $(n=8)$ than in $\mathrm{NBM}^{\mathrm{CD} 34+/ \mathrm{CD} 19+}(n=4)$ progenitors (Figure $\left.2 \mathrm{~A}\right)$. Thus enhanced SET expression represents a common mechanism used by both p210 (26) and p190 BCR/ABL oncoproteins to suppress the phosphatase activity of PP2A, a tumor suppressor with a pivotal role in the regulation of cell cycle progression, survival, and differentiation $(38,39)$.

While imatinib treatment suppresses BCR/ABL kinase activity only (Figure 2B, lanes 1 and 2), enhanced PP2A activity by FTY720 treatment $\left(2.5 \mu \mathrm{M}\right.$; cell lines, 36 hours; CML-BC ${ }^{\mathrm{CD} 34+}$, 48 hours) abolished $\mathrm{p} 210^{\mathrm{BCR} / \mathrm{ABL}}$ phosphorylation and induced downregulation of $\mathrm{p} 210^{\mathrm{BCR} / \mathrm{ABL}}$ in imatinib-sensitive (32D-p210 $10^{\mathrm{BCR} / \mathrm{ABL}}$ and $\mathrm{K} 562$ ) and -resistant [32D-p210 $\mathrm{BCR} / \mathrm{ABL}$ (T315I)] cell lines (Figure 2B, lanes $3-8)$ and in primary CML-BC ${ }^{\mathrm{CD} 34+}$ cells $(n=3)$ (Figure $2 \mathrm{~B}$, lanes 12 and 13). The PP2A-mediated effects of FTY720 were also clearly evident in the BaF3-p190 BCR/ABL cell line and Ph1 ALL ${ }^{\mathrm{CD} 34+/ \mathrm{CD} 19+}$ patient cells $(n=6)$. In fact, $\mathrm{p} 190^{\mathrm{BCR} / \mathrm{ABL}}$ tyrosine phosphorylation and expression were strongly inhibited in BaF3-p190 ${ }^{\mathrm{BCR} / \mathrm{ABL}}$ and IL-7-cultured Ph1 ALL ${ }^{\text {CD34+/CD19+ }}$ cells treated with $2.5 \mu \mathrm{M}$ FTY720 for 36 and 48 hours, respectively (Figure 2B, lanes 9-11, 14, and 15). Likewise, 1,9-dideoxyforskolin ( $40 \mu \mathrm{M}$; 96 hours), a PP2A activator capable of impairing p $210^{\mathrm{BCR} / \mathrm{ABL}}$ expression and leukemogenesis (26), efficiently suppressed $\mathrm{p} 190^{\mathrm{BCR} / \mathrm{ABL}}$ activity and expression in BaF3-p190 $19 \mathrm{BCR} / \mathrm{ABL}$ (Figure 2B, lane 10) and IL-7-cultured Ph1 $\mathrm{ALL}^{\mathrm{CD} 34+/ \mathrm{CD} 19+}$ cells (data not shown).

To further demonstrate that the FTY720-induced suppression of $\mathrm{BCR} / \mathrm{ABL}$ activity and expression depends on activation of PP2A, parental and $\mathrm{BCR} / \mathrm{ABL}$-expressing 32Dcl3 cells were transduced with a retrovirus (pBABE-GFP-sTAg) carrying the SV40 small T antigen (small-t) that, as reported, inhibits PP2A activity upon interaction with the $\mathrm{PP} 2 \mathrm{~A}_{\mathrm{AC}}$ dimer (PP2A dimer containing the catalytic $\mathrm{C}$ subunit associated with the structural A subunit) and 
A

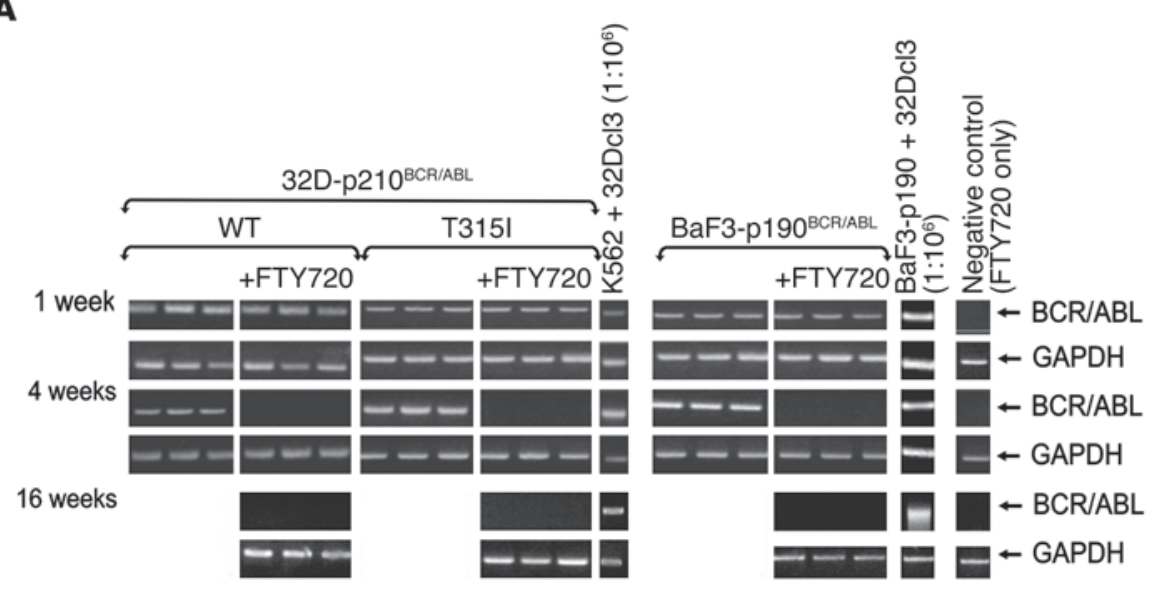

4 weeks

(I) Age-matched mice

3) FTY720

DD 32D-p210 $0^{\text {BCRABL }}(\mathrm{T} 315 \mathrm{I})$

บ1) $32 \mathrm{D}-\mathrm{p} 210^{\text {BCRABL }}(\mathrm{T} 315 \mathrm{I})+\mathrm{FTY} 720$

1) $\begin{aligned} & \text { FTY720 } \\ & 32 \mathrm{D}-\mathrm{p} 210^{\text {вcR/ABL }}\end{aligned}$

()) $32 \mathrm{D}-\mathrm{p} 210^{\text {BCRABL }}+\mathrm{FTY} 720$

(1) FTY720

21 BaF3-p190 19 BCRABL

211 BaF3-p190 $0^{\text {BCPABL }}+$ FTY720

B

Controls

32D-p210 ${ }^{\text {BCR/ABL }}$
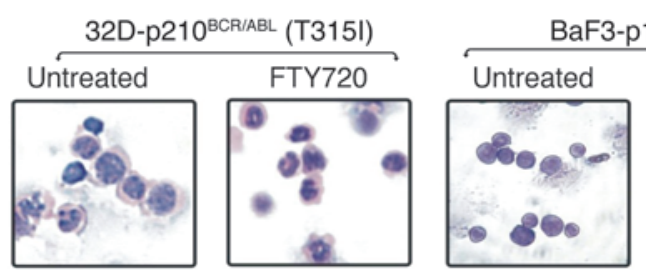

BaF3-p190 BCA/ABL
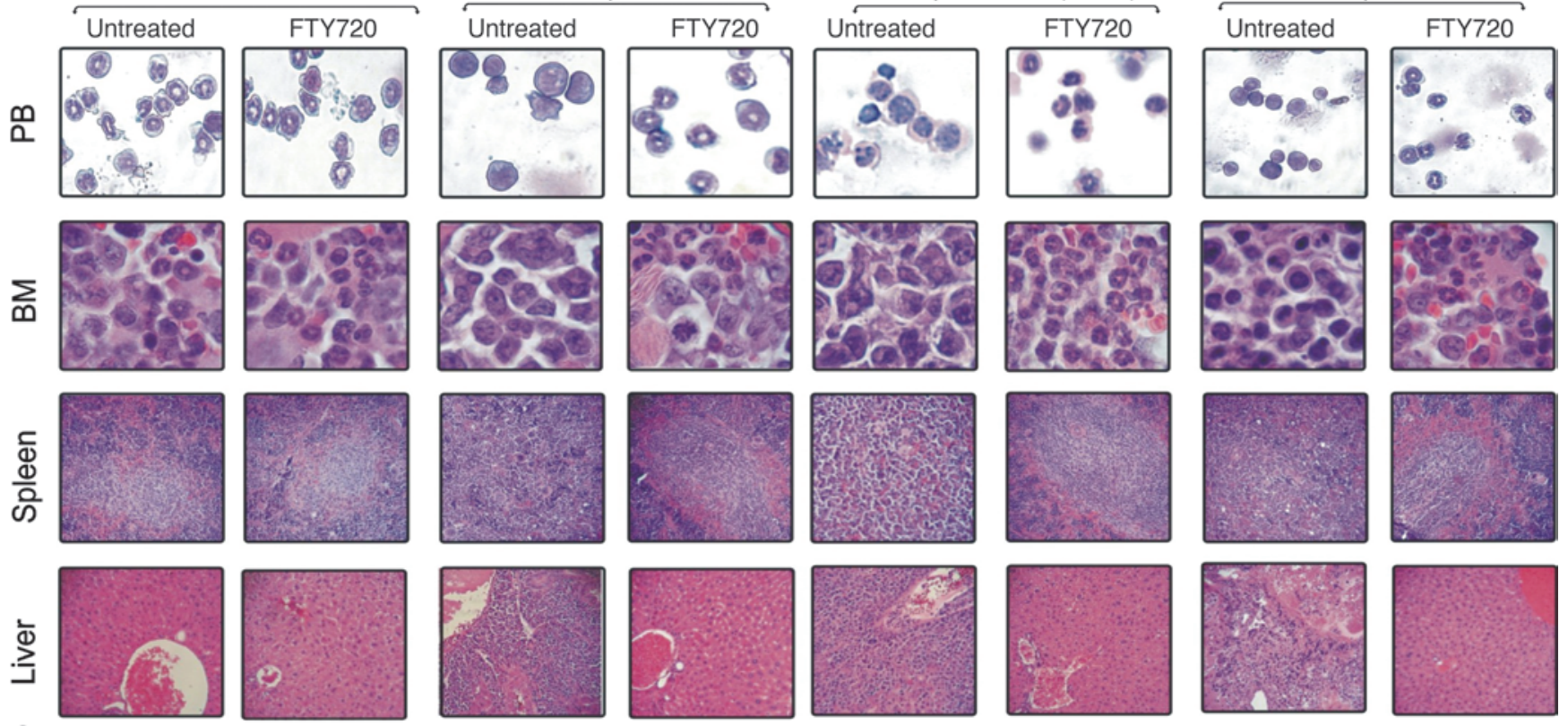

C
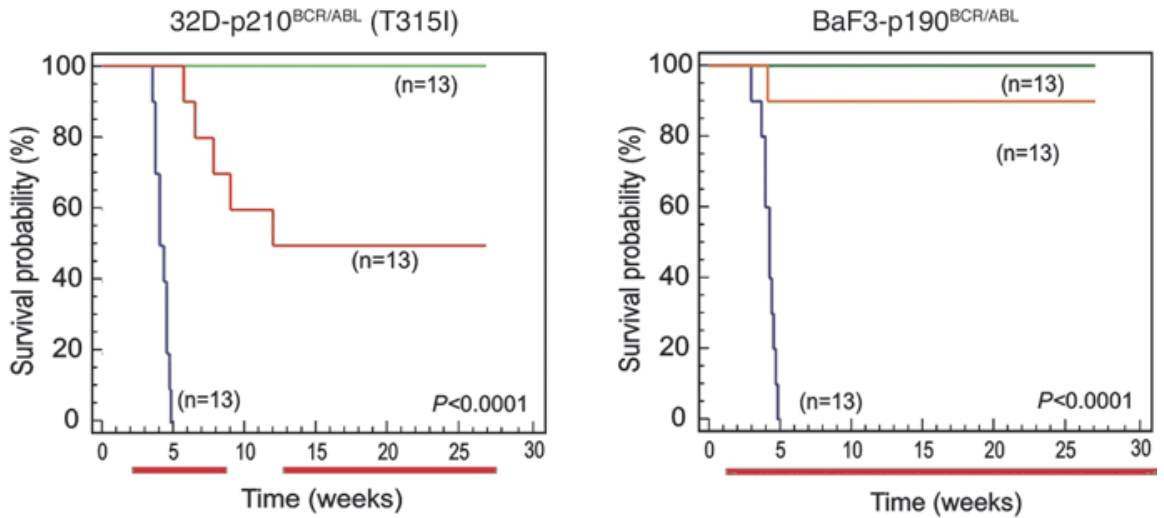
( - treatment schedule )

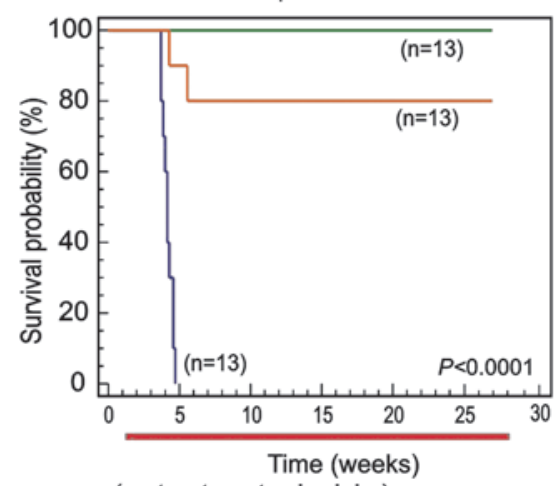

- FTY720 only; - Cells only - Cells + FTY720 FTY720 (10 mg/Kg/d; i.p.) 


\section{Figure 6}

Pharmacologic doses of FTY720 impair in vivo imatinib/dasatinib-sensitive and -resistant p210 and p190 BCR/ABL leukemogenesis. (A) Left: Nested RT-PCR for p210 and p190 BCR/ABL indicates the presence of BCR/ABL-expressing cells in the PB of untreated and FTY720-treated mice. Nested RT-PCR performed with RNA from PB of mice treated with FTY720 only (far right lane) and with RNA from a 1:106 dilution of K562 or BaF3p190 (BCR/ABL+ cells) with 32Dcl3 cells were used, respectively as negative and positive controls. GAPDH mRNA levels were used as a control. Right panel: Visual analysis of spleens from age-matched and FTY720-treated mice and untreated and FTY720-treated mice injected with the indicated cell lines. (B) May-Grumwald/Giemsa staining of PB and H\&E staining of sections from bone marrow, spleen, and liver of untreated and FTY720-treated (4 weeks) control and cell-injected mice. Original magnification, $\times 400$ (PB and bone marrow); $\times 250$ (liver and spleen). (C) Effect of $10 \mathrm{mg} / \mathrm{kg} / \mathrm{d}$ FTY720 on survival of SCID mice i.v. injected with the indicated cells lines $(n=13$; orange lines). Mice injected with cells only ( $n=13$; blue lines) or drug only ( $n=13$; green lines) were used as controls. The red lines below each graph indicate the treatment regimen. Survival was calculated by the Kaplan-Meier method, and the log-rank test evaluated the differences among survival distributions. Overall, $P<0.0001$; 32D-p210BCR/ABL untreated versus FTY720-treated, $P<0.0001$; 32D-p210BCR/ABL (T315I) untreated versus FTY720-treated, $P<0.001$; and BaF3-p190BCR/ABL untreated versus FTY720-treated, $P<0.0001$.

the free $\mathrm{PP} 2 \mathrm{~A}_{\mathrm{A}}$ subunit (PP2A structural/regulatory subunit A) (40). Expression of small-t (Figure 2C) abrogated the effects of FTY720; in fact, FTY720 treatment $(2.5 \mu \mathrm{M})$ was unable to rescue PP2A activity (Figure 2C) or suppress BCR/ABL activity or expression (Figure $2 \mathrm{C}$, right panel, lane 4) in $\mathrm{GFP}^{+}$small-t-expressing 32D-BCR/ABL cells. Moreover, small-t markedly impaired PP2A activity in 32Dcl3 cells, whereas it did not further decrease PP2A activity in 32D-BCR/ABL cells (Figure 2C) or have any effect on $\mathrm{BCR} / \mathrm{ABL}$ activity or expression (Figure $2 \mathrm{C}$, right panel, lane 3 ). As expected, FTY720 treatment was also unable to rescue PP2A activity in small-t-expressing 32Dcl3 cells (Figure 2C), whereas it significantly augmented PP2A activity (Figure 2C) and inhibited $\mathrm{BCR} / \mathrm{ABL}$ activity and expression (Figure $2 \mathrm{C}$, right panel, lane 2) in $\mathrm{PBABE}-\mathrm{GFP}$ vector-transduced 32D-BCR/ABL cells.

FTY720 inhibits $B C R / A B L$ and its major signal transducers through a PP2A-dependent mechanism. Activation of PP2A is an early event induced by FTY720 in BCR/ABL cells (Figure 3A, lanes 1 and 3). Consistent with the effects of PP2Ac overexpression or SET downregulation in 32D-p210 ${ }^{\mathrm{BCR} / \mathrm{ABL}}$ cells (26), FTY720 treatment $(2.5 \mu \mathrm{M}$; 6 hours) also negatively affected phosphorylation (activity) of the BCR/ABL $(8,41)$ and PP2A $(42-44)$ targets Akt, STAT5, and ERK1/2 without altering their expression levels (Figure 3A). Moreover, treatment with the serine-threonine phosphatase inhibitor okadaic acid ( $0.25 \mathrm{nM} ; 1.5$ hours) at concentrations that specifically inhibit the activity of PP2A but not that of other cellular phosphatases (45) restored BCR/ABL activity and expression and rescued Akt, STAT5, and ERK1/2 phosphorylation in FTY720treated 32D-p210 $\mathrm{BCR} / \mathrm{ABL}$ cells (Figure 3A, lane 5). The PP2A activator 1,9-dideoxyforskolin also suppressed $\mathrm{BCR} / \mathrm{ABL}$ activity and expression and inactivated the major BCR/ABL signal transducers (i.e., Akt, STAT5, and ERK1/2) in an okadaic acid-sensitive manner (Figure 3A, lanes 2 and 4).

FTY720-dependent inactivation of BCR/ABL does not require FTY720 phosphorylation. FTY720, like sphingosine, undergoes phosphorylation by the sphingosine kinases (SPHKs) (28-31); sphingosine1-phosphate (S1P) and phosphorylated FTY720 (FTY720-P) are exported outside the cells where, upon interaction with the Gi protein-coupled S1P receptor 1 (S1PR1), they become internalized and allow Gi protein-mediated signaling $(28-31,46)$. To determine whether the FTY720-induced suppression of BCR/ABL activity depends on the FTY720 interaction with the Gi protein-coupled S1PR1 (46) and/or conversion to FTY720-P (36), we pretreated 32D-p210 ${ }^{\mathrm{BCR} / \mathrm{ABL}}$ and BaF3-p190 ${ }^{\mathrm{BCR} / \mathrm{ABL}}$ cells with an excess of S1P (100 nM; 1 hour) (47) and then exposed them to FTY720 (2.5 $\mu \mathrm{M}$; 24 hours). As controls, cells were either left untreated or treated only with $2.5 \mu \mathrm{M}$ FTY720 or $100 \mathrm{nM}$ S1P for the same period of time.
As shown, while FTY720 alone induced marked BCR/ABL dephosphorylation and downregulation, pretreatment with $100 \mathrm{nM}$ S1P prevented FTY720 from exerting its effect on both p210 and p190 BCR/ABL oncoproteins (Figure 3B, lanes 1-4 and 6). Notably, treatment with $100 \mathrm{nM}$ S1P alone was unable to suppress both p210 and p190 BCR/ABL activity (Figure 3B, lane 5). Furthermore, inhibition of the Gi protein-coupled S1PRs with pertussis toxin (PTX; $100 \mathrm{ng} / \mathrm{ml}$ ) (48) did not counteract the effects of FTY720 on BCR/ABL expression and activity (Figure 3D, lane 7), suggesting that the effect of FTY720 on BCR/ABL is not mediated by Gi-coupled S1PR-induced signals.

To determine whether the PP2A-mediated effects of FTY720 might rely on its phosphorylation, we preincubated 32Dp210 $\mathrm{BCR} / \mathrm{ABL}$ and/or BaF3-p190 $\mathrm{BCR} / \mathrm{ABL}$ cells with either the SPHK1 and SPHK2 antagonist (49) $N^{\prime}, N$-dimethylsphingosine (DMS; $2.5 \mu \mathrm{M}, 30$ minutes) at a concentration that does not inhibit growth of myeloid leukemic cells (50) or with the specific SPHK inhibitor $2(0.5 \mu \mathrm{M})(51)$. Unexpectedly, FTY720-induced p210 and/or $190 \mathrm{BCR} / \mathrm{ABL}$ inactivation was not prevented but augmented by both DMS (Figure 3C) and SPHK inhibitor 2 (Figure $3 \mathrm{D}$, lanes 3 and 4 ) treatment, suggesting that the nonphosphorylated FTY720 is responsible for BCR/ABL inactivation. In addition, BCR/ABL dephosphorylation was also observed after cotreatment of 32D-BCR/ABL cells with $2.5 \mu \mathrm{M}$ FTY720 and fumonisin B1 $(25 \mu \mathrm{M})$, a ceramide synthetase inhibitor, but not after administration of fumonisin B1 only (Figure 3D, lanes 5 and 6), suggesting that FTY720 does not activate PP2A by stimulation of the ceramide pathway.

Antileukemic activity of FTY720 in imatinib and dasatinib-sensitive and/or -resistant primary $\mathrm{Pb} 1$ leukemia cells and $B C R / A B L^{+}$cell lines. To assess the biologic effects and therapeutic relevance of FTY720 in $\mathrm{Ph} 1$ leukemias, imatinib-sensitive and -resistant myeloid [32Dp210 $\mathrm{BCR} / \mathrm{ABL}, 32 \mathrm{D}-\mathrm{p} 210^{\mathrm{BCR} / \mathrm{ABL}}$ (T315I), and Ph1 K562] and lymphoid (BaF3-p190 $\mathrm{BCR} / \mathrm{ABL}) \mathrm{BCR} / \mathrm{ABL}^{+}$cell lines as well as primary bone marrow progenitors from imatinib-sensitive and -resistant CML-BC, imatinib-sensitive and -resistant CML-CP, and Ph1 ALL patients $\left[\mathrm{CML}-\mathrm{BC}^{\mathrm{CD} 34+}, n=11\right.$; CML-BC ${ }^{\mathrm{CD} 34+}(\mathrm{T} 315 \mathrm{I}), n=1$; CML$\mathrm{CP}^{\mathrm{CD} 34+}, n=3$; CML-CPCD34+ $(\mathrm{T} 315 \mathrm{I}), n=1$; and Ph1 ALL ${ }^{\mathrm{CD} 34+} / \mathrm{CD} 19+$, $n=12$ ) were treated with $2.5 \mu \mathrm{M}$ FTY720 for 36 hours (for cytokine-independent cell lines) or 48-96 hours (for patient cells cultured and treated in the presence of cytokines) and used to assess apoptosis and/or clonogenic potential. For controls we used cytokine-cultured myeloid 32Dcl3, lymphoid BaF3, and normal CD $34^{+}$and $\mathrm{CD} 34^{+} / \mathrm{CD} 19^{+}$progenitors $\left(\mathrm{NBM}^{\mathrm{CD} 34+}\right.$ and $\left.\mathrm{NBM}^{\mathrm{CD} 34+/ \mathrm{CD} 19+} ; n=8\right)$ treated with FTY720 at the concentration and time indicated above. 


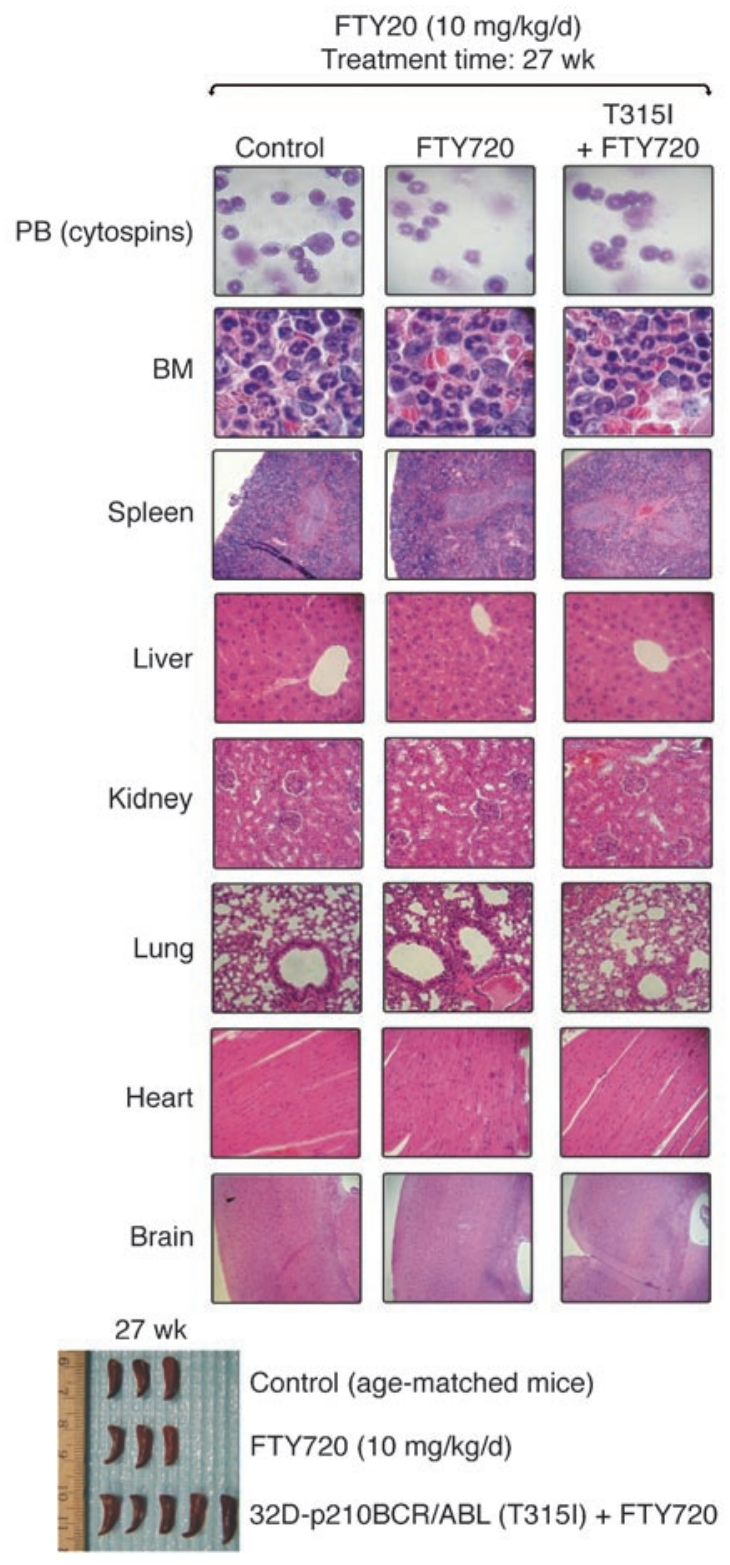

Consistent with its ability to strongly enhance PP2A activity in Ph1positive but not in normal hematopoietic progenitors (Figure 2A), FTY720 markedly suppressed growth (data not shown) and induced apoptosis (Figure 4) of cytokine-deprived imatinib-sensitive and -resistant myeloid and lymphoid $\mathrm{BCR} / \mathrm{ABL}^{+}$cell lines and of IL-3/IL-6/Flt-3L/KL-cultured and IL-7/Flt-3L/KL-cultured $\mathrm{CML}-\mathrm{BCCD} 34+^{(n=3)}$ and Ph1 ALLCD34+/CD19+ $(n=3)$ patient cells. A similar proapoptotic effect was observed in $\mathrm{CML}_{-} \mathrm{CP}^{\mathrm{CD} 34+}(n=3)$ cells treated with $2.5 \mu \mathrm{M}$ FTY720 (Figure 4). In fact, the percentage of apoptosis (annexin $\mathrm{V}^{+}$cells) in FTY720-treated p210 BCR/ABL ${ }^{+}$ cell lines, primary CML-BC ${ }^{\mathrm{CD} 34+}$ and $\mathrm{CML}-\mathrm{CP}^{\mathrm{CD} 34+}$ cells ranged between 83\% and 97\% (Figure 4A). FTY720-treated BaF3-p190 BCR/ABL and Ph1 ALL ${ }^{\mathrm{CD} 34+/ \mathrm{CD} 19+}$ cells also underwent marked cell death ( $\geq 98 \%$ annexin $\mathrm{V}^{+}$cells) (Figure $4 \mathrm{~B}$ ). By contrast, the percentages of apoptotic (annexin $\left.\mathrm{V}^{+}\right) 32 \mathrm{Dcl} 3, \mathrm{BaF}, \mathrm{NBM}^{\mathrm{CD} 34+}(n=3)$, and $\mathrm{NBM}^{\mathrm{CD} 34+/ \mathrm{CD} 19+}(n=3)$ cells were not significantly altered in FTY720-treated cells compared with untreated cells (Figure 4).

\section{Figure 7}

Effects of long-term FTY720 administration in healthy and p210 T315I BCR/ABL-injected mice. Top: May-Grumwald/Giemsa staining of PB cytospins and H\&E staining of tissue sections from bone marrow, spleen, liver, kidney, lung, heart, and brain. Bottom: Visual analysis of spleens from age-matched and FTY720-treated controls and 32Dp210BCR/ABL (T315I) cell-injected mice euthanized 27 weeks after the beginning of treatment. Original magnification, $\times 400$ (PB and bone marrow); ×250 (spleen, liver, kidney, lung, heart, and brain).

Because inhibition of the BCR/ABL-dependent PI3K/Akt pathway triggers caspase-dependent apoptosis (8), strong activation of caspase-3/7 was observed in FTY720-treated p210 and p190 BCR/ ABL-transformed cell lines (an average of 65-fold increase) and in cytokine-cultured CML-BC ${ }^{\mathrm{CD} 34+}(n=3), \mathrm{CML}^{-\mathrm{CP}^{\mathrm{CD}} 34+}(n=3)$, and $\mathrm{Ph} 1 \mathrm{ALL}^{\mathrm{CD} 34+/ \mathrm{CD} 19+}(n=3)$ cells (an average of 6-fold increase) but not in nontransformed cell lines or normal hematopoietic progenitors $(n=6)$ (Figure 4, A and B).

Similar to the inhibitory effect of forskolin or ectopic PP2Ac expression on colony formation of CML-BC ${ }^{\mathrm{CD} 34+}$ patient cells (26), both myeloid 32D-p210 $\mathrm{BCR} / \mathrm{ABL}$ (wild-type and T315I) and lymphoid BaF3p190 BCR/ABL cells showed 70\%-98\% suppression of clonogenic potential when exposed to a single dose of FTY720 $(2.5 \mu \mathrm{M})$ (Figure $5 \mathrm{~A})$. Likewise, FTY720 strongly abolished (80\%-95\% inhibition) the ability of primary imatinib-sensitive and imatinib- and dasatinib-resistant $\mathrm{CML}-\mathrm{BC}^{\mathrm{CD} 34+}(n=11)$ and $\mathrm{CML}-\mathrm{CP}^{\mathrm{CD} 34+}(n=3)$ marrow cells to form IL-3-derived colonies in semisolid medium (Figure 5B). Also, IL-7-driven colony formation of Ph1 ALL CD34+/CD19+ lymphoid progenitors $(10,52)(n=12)$ was dramatically suppressed (an average of $80 \%$ inhibition) by exposure to $2.5 \mu \mathrm{M}$ FTY720. Moreover, the presence of malignant cells bearing the T315I BCR/ABL mutant did not influence the responsiveness of bone marrow CD34+ $\mathrm{CML}-\mathrm{CP}$ $(n=1)$ or CML-BC $(n=3)$ cells to FTY720 (Figure $5 \mathrm{~B})$. Conversely, FTY720 did not affect the IL-3- or IL-7-driven clonogenic potential of $\mathrm{NBM}^{\mathrm{CD} 34+}(n=4)$ or $\mathrm{NBM}^{\mathrm{CD} 34+/ \mathrm{CD} 19+}(n=4)$ cells, respectively. Consistent with the important role of PP2A as mediator of the in vitro cytotoxic effect of FTY720, cotreatment with $2.5 \mu \mathrm{M}$ FTY720 and $0.25 \mathrm{nM}$ okadaic acid significantly rescued cytokine-dependent colony formation of CML-CPCD34+, CML-BCCD34+, and Ph1 $\mathrm{ALL}^{\mathrm{CD} 34+/ \mathrm{CD} 19+}$ bone marrow progenitors (Figure 5C). Note that at $0.25 \mathrm{nM}$ okadaic acid specifically inhibits PP2A activity only (45). Interestingly, replating of residual colonies from FTY720-treated $\mathrm{BCR} / \mathrm{ABL}^{+}$cells in $2.5 \mu \mathrm{M}$ FTY720-containing semisolid cultures resulted in $90 \%$ or greater inhibition of colony formation (data not shown), suggesting that emergence of FTY720 resistance does not account for the presence of residual colonies.

Long-term treatment with FTY720 remarkably suppresses in vivo p210 (wild-type and T315I) and $p 190$ BCR/ABL leukemogenesis without exerting adverse effects. Although xenografts of primary CML-BC and Ph1 ALL progenitors in NOD-SCID mice represent the best models to assess the effect of FTY720 on p210 and p190 BCR/ABL-driven leukemogenesis, this approach was limited by the insufficient availability of patient cells. Therefore, we used comparable mouse models of CML-BC and Ph1 ALL. SCID mice $(n=78)$ were i.v. injected with $32 \mathrm{D}-\mathrm{p} 210^{\mathrm{BCR} / \mathrm{ABL}}, \mathrm{BaF} 3-\mathrm{p} 190^{\mathrm{BCR} / \mathrm{ABL}}$, or 32D-p210 $10^{\mathrm{BCR} / \mathrm{ABL}}$ (T315I) cells $\left(5 \times 10^{5}\right.$ cells/mouse $)$. After 7 days, $\mathrm{BCR} / \mathrm{ABL}^{+}$cell engraftment was assessed by the presence of circulating BCR/ $\mathrm{ABL}^{+}$cells via nested RT-PCR-mediated detection of $\mathrm{p} 210$ or p190 BCR/ABL transcripts in peripheral blood (PB) (Figure 6A). 
Table 1

Blood counts in FTY720-treated mice transplanted with T315I BCR/ABL+ leukemic cells

$\begin{array}{lcccc} & \text { Untreated }(\boldsymbol{n}=\mathbf{3}) & \text { FTY720-treated }(\boldsymbol{n}=\mathbf{3}) & \text { T315I + FTY720-treated }(\boldsymbol{n}=\mathbf{5}) & \boldsymbol{P} \text { value } \\ \text { rbc }\left(10^{12} \text { cells } / \mathrm{l}\right) & 7.84(1.04) & 8.26(0.87) & 9.09(1.07) & 0.24 \\ \text { Nucleated cells }\left(10^{9} / \mathrm{l}\right) & 0.87(0.25) & 1.13(0.15) & 1.64(0.51) \\ \text { Platelet count } & 157,333(66,905) & 158,666(35,360) & 0.53 \\ \text { Neutrophils }\left(10^{9} \text { cells/l) }\right. & 0.43(0.15) & 0.44(0.30) & 0.70(0.10)\end{array}$

Analysis performed using Kruskal-Wallis test. Values shown are the mean, with SD in parentheses.

The i.p. treatment with FTY720 $\left(10 \mathrm{mg} / \mathrm{kg} / \mathrm{d} ; \mathrm{LD}_{50}[50 \%\right.$ lethal dose $]=300 \mathrm{mg} / \mathrm{kg}$ ) was then initiated in 13 mice per group $(n=39)$. As controls, 13 mice per group $(n=39)$ only received daily treatment with FTY720, whereas an identical number of cell-injected mice were left untreated.

After 4 weeks of FTY720 treatment, all treated leukemic mice were alive and BCR/ABL negative (Figure 6A), whereas only 3-4 untreated leukemic mice were alive but appeared lethargic and were $\mathrm{BCR} / \mathrm{ABL}^{+}$ (Figure 6A). Thus, 3 mice per group were sacrificed and organs were evaluated by visual inspection and light microscopy. Mice injected with wild-type or T315I p210 and p190 BCR/ABL ${ }^{+}$cells showed massive splenomegaly, whereas, consistent with the antileukemic effect of other PP2A activators (26), the morphology of spleens from FTY720-treated BCR/ABL ${ }^{+}$cell-injected mice resembled that of control age-matched or FTY720-only treated mice (Figure 6A). PB cytospins and $\mathrm{H} \& \mathrm{E}$-stained sections of spleen, bone marrow, and liver of 32D-p210 BCR/ABL, 32D-p210 BCR/ABL (T315I), and BaF3-p190 BCR/ABL mice treated with vehicle (saline solution) showed extensive infiltration of blast cells with a low degree of myeloid maturation and presence of a large number of circulating blast cells typical of an overt acute myeloid leukemia-like process (Figure 6B). In contrast, spleen, liver, and bone marrow histopathology and $\mathrm{PB}$ from the FTY720-treated leukemic mice (Figure 6B) were similar to that of the age-matched and FTY720-injected control groups (Figure 6B). Consistent with these findings, $80 \%$ and $90 \%$ of FTY720-treated mice injected with $32 \mathrm{D}-\mathrm{p} 210^{\mathrm{BCR} / \mathrm{ABL}}$ or $\mathrm{BaF} 3-\mathrm{p} 190^{\mathrm{BCR} / \mathrm{ABL}}$ cells, respectively, were BCR/ABL-negative at 16 weeks (Figure $6 \mathrm{~A}$ ) and all were alive 27 weeks (6.3 months) after transplant (Figure 6C). By contrast, the median survival of mice injected with 32D-p210 $\mathrm{BCR} / \mathrm{ABL}$ or BaF3-p190 ${ }^{\mathrm{BCR} / \mathrm{ABL}}$ cells only was 4.3 and 4.1 weeks, respectively (Figure 6C). Similarly, all untreated 32D-p210 BCR/ABL (T315I) mice died within 5 weeks (median survival, 4.8 weeks) (Figure 6C), while $80 \%$ of FTY720-treated T315I mice were alive after 8 weeks of treatment. Unexpectedly, upon suspension of drug administration, $30 \%$ of mice relapsed and died of a $\mathrm{BCR} / \mathrm{ABL}^{+}$acute leukemia-like disease process within 4 weeks of the end of treatment (Figure 6C and Supplemental Figure 1). As already observed with 1,9-dideoxyforskolin treatment (26), resumed FTY720 therapy prevented further mortalities, restored the BCR/ABL-negative status (as assessed by nested RT-PCR performed 16 weeks following transplant on PB of FTY720-treated T315I-injected mice; Figure 6A), and resulted in $100 \%$ survival of treated mice at 27 weeks (6.3 months) after cell injection (Figure 6C). As expected, 100\% of control mice were still alive after 27 weeks of daily i.p. treatment with FTY720 $(10 \mathrm{mg} / \mathrm{kg})$ (Figure 6C). Furthermore, no significant changes in body weight (data not shown) and no signs of toxicity were observed in control or T315I SCID mice that received $10 \mathrm{mg} / \mathrm{kg}$ FTY720 for 27 weeks (Figure 7). In fact, hematological data showed neither altered myelopoiesis nor biochemical (e.g., hemoglobin, MCV, MCHC) abnormalities in control or T315I mice treated for 27 weeks with $10 \mathrm{mg} / \mathrm{kg} / \mathrm{d}$ FTY720. Moreover, PB cytospins from these 2 FTY720treated groups compared with untreated age-matched mice did not show noticeable differences in blood cellularity (Figure 7). Specifically, the numbers of erythrocytes ( $\mathrm{rbc}$ ), platelet, nucleated cells, and neutrophils were not significantly different (Kruskal-Wallis test) among untreated control $(n=3)$, FTY720-treated control $(n=3)$, or FTY720-treated T315I $(n=5)$ mice (Table 1$)$. As expected, PB blast cells were not detected in FTY720-treated T315I mice (data not shown). Furthermore, no gross or microscopic differences in spleen size or architecture; bone marrow cellularity; or liver, kidney, lung, heart, or brain structure were observed in FTY720-treated (27 weeks; control and T315I) mice compared with untreated age-matched control mice (Figure 7).

\section{Discussion}

Although a possible role for the immunomodulator and PP2A activator FTY720 as an anticancer agent has been proposed for many solid tumors (53-57), its therapeutic potential in hematologic malignancies, including $\mathrm{Ph} 1$ leukemias, and the molecular mechanisms whereby it preferentially targets cancer cells have been only minimally investigated. Here we provide evidence bolstering the therapeutic use of FTY720 in imatinib/dasatinib-sensitive and -resistant (T315I included) CML-BC and Ph1-positive ALL. Specifically, we demonstrate that growth inhibition and induction of caspase-dependent apoptosis by FTY720 depend on interference with p210 and p190 BCR/ABL oncogenic activity. In fact, the FTY720 antiproliferative and proapoptotic effects are preceded by a marked decrease of p210/p190 BCR/ABL activity and expression. However, while FTY720 induces apoptosis in several carcinomas, glioma, and multiple myeloma cells with $\mathrm{IC}_{50}(50 \%$ inhibitory concentration) ranging between 5 and $18 \mu \mathrm{M}(53-55,57,58)$, its inhibitory effects on cell growth and $\mathrm{BCR} / \mathrm{ABL}$ oncogenic kinase activity occurs at nanomolar and low micromolar concentrations $\left[\mathrm{EC}_{50}=80 \mathrm{nM}\right]$ that reportedly do not impair viability of normal human myeloid and lymphoid cells (reviewed in refs. 28, 29, 31), thereby indicating that fewer hematologic toxicities might be found in treated leukemic patients. In addition, these doses more closely resemble the FTY720 blood concentrations achieved in patients undergoing renal organ transplant (35).

The mechanism whereby FTY720 antagonizes BCR/ABL activity and expression in primary CML-BC and Ph1 ALL depends on reactivation of PP2A activity (Figures 2, 3, and 5). In this regard, we also show that inhibition of PP2A tumor suppressor activity occurs also in Ph1 ALL progenitors in a SET-dependent manner. Consistent with the role of PP2A as mediator of the FTY720 effects in Ph1 leukemic progenitors, it has been reported that FTY720 
activates PP2A through interaction with purified PP2 $\mathrm{A}_{\mathrm{AC}}$ dimers (27) and that rescue of PP2A activity induces the SHP-1-dependent p210-BCR/ABL dephosphorylation and proteasome-dependent degradation (26). Furthermore, the evidence that SV40 small-t prevents the FTY720-induced BCR/ABL inactivation and degradation, together with the ability of picomolar concentrations of okadaic acid (a specific inhibitor of PP2A serine threonine phosphatase when used at $0.25 \mathrm{nM}$ concentration; ref. 45) to rescue the clonogenic potential of $\mathrm{CD} 34^{+} \mathrm{CML}-\mathrm{CP}, \mathrm{CML}-\mathrm{BC}$, and $\mathrm{Ph} 1 \mathrm{ALL}$ progenitors and restore both activity and expression of $\mathrm{BCR} / \mathrm{ABL}$ and phosphorylation of BCR/ABL and PP2A targets Akt, STAT5, and ERK1/2 in FTY720- and 1,9-dideoxyforskolin-treated (26) BCR/ABL ${ }^{+}$cells strongly indicates that FTY720 functions through activation of PP2A. Accordingly, Akt dephosphorylation appears essential for the proapoptotic activity of FTY720 in leukemic myeloid U937 and lymphoid BALL-1 cells (27). Indeed, okadaic acid abolished FTY720-induced apoptosis and rescued Akt phosphorylation in these leukemia cells (27). Similarly, FTY720 induces ERK1/2 dephosphorylation in renal cells (59). Thus it is likely that the therapeutic potential of the PP2A activator FTY720 in Ph1 leukemias is based on its ability to shut down BCR/ABL kinase activity and expression while concurrently abolishing the activity of other direct (e.g., Akt and ERK) and indirect (e.g., STAT5) PP2A targets (42-44) that are essential for p210 and p190 $\mathrm{BCR} / \mathrm{ABL}$ leukemogenic potential $(8,60)$. In addition, these data further support the concept that functional inactivation of the PP2A tumor suppressor represents an essential mechanism used by $\mathrm{BCR} / \mathrm{ABL}$ oncoproteins for sustaining high levels of activity and expression in CML-BC and Ph1 ALL progenitors.

To assess whether the molecular mechanisms by which FTY720 exerts its immunomodulatory and anticancer activities are identical or follow 2 different signaling pathways, we investigated the effects of S1P and the SPHK inhibitors DMS and SPHK inhibitor 2 on BCR/ABL activity and expression. Reportedly, immunomodulation by FTY720 is achieved at nanomolar concentrations and requires the interaction of FTY720-P phosphorylated by SPHK2 with the Gi protein-coupled S1PRs $(29,36,61)$. Conversely, in different solid tumor and multiple myeloma cell lines, the proapoptotic effects of FTY720 may not require FTY720 phosphorylation and may occur at high micromolar levels $(\geq 10 \mu \mathrm{M})$ through a S1PRindependent, ceramide-dependent apoptotic pathway $(28,57)$. In $\mathrm{BCR} / \mathrm{ABL}^{+}$cells, exposure to S1P prevented the FTY720-induced PP2A-dependent BCR/ABL dephosphorylation and downregulation (Figure $3 \mathrm{~B}$ ). Because exposure of $\mathrm{BCR} / \mathrm{ABL}^{+}$cells to $\mathrm{S} 1 \mathrm{P}$ alone did not alter BCR/ABL activity or expression (Figure $3 \mathrm{~B}$ ), the blocking activity of S1P may suggest that the PP2A-mediated effects of FTY720 could rely on its interaction with the Gi protein-coupled S1PRs. However, the inability of PTX (inhibitor of Gi protein-coupled receptor activity) to prevent the FTY720induced $\mathrm{BCR} / \mathrm{ABL}$ inactivation argues against the involvement of Gi protein-coupled S1PR1 in mediating FTY720 antileukemic activity. Furthermore, the FTY720-induced inactivation and downregulation of p210/p190 BCR/ABL oncoproteins was not prevented but augmented by treatment with 2 different SPHK inhibitors (Figure 3, C and D). This may result from inhibition of SPHKs, which diminish endogenous S1P and enhance nonphosphorylated FTY720 levels. Altogether these results suggest that BCR/ABL inactivation requires neither SPHK-dependent FTY720 phosphorylation nor the triggering of Gi protein-coupled S1PRmediated signaling. However, based on the ability of S1P to pre- vent FTY720 from inducing BCR/ABL inactivation, we cannot exclude that nonphosphorylated FTY720 may interact with those receptors and, upon internalization, elicit signals that are different from those initiated by S1P. In this regard, it has already been shown that nonphosphorylated FTY720 can also interact with the S1PRs (36). Additionally, although high micromolar doses of FTY720 trigger apoptosis through increased ceramide levels $(62,63)$ that, in turn, are capable of inducing PP2A activity $(64)$, it is also unlikely that the FTY720-induced PP2A activation is mediated by a perturbation of the sphingosine-ceramide cycle. In fact, inhibition of ceramide synthetase with fumonisin B1 (65) did not inhibit the BCR/ABL dephosphorylation induced by FTY720 treatment (Figure 3D).

Furthermore, because FTY720 inhibits BCR/ABL activity with an $\mathrm{EC}_{50}$ in the nanomolar range (Figure 1), our data argue against the simplistic interpretation that nonphosphorylated FTY720 is not apoptotic at these pharmacologically active doses and suggest that the growth inhibitory and apoptotic effects of FTY720 are strictly dependent on the functional status of PP2A. In this scenario, Ph1 leukemic blast cells but not normal hematopoietic progenitors are sensitive to nanomolar concentrations of FTY720 because they lack or have markedly reduced PP2A activity (Figure 2). However, whether FTY720 directly or indirectly interacts with $\mathrm{PP} 2 \mathrm{~A}_{\mathrm{AC}}$ dimers in $\mathrm{BCR} / \mathrm{ABL}^{+}$cells still remains to be elucidated.

In p210 and p190 BCR/ABL-expressing myeloid and lymphoid cell lines and in patient-derived primary $\mathrm{CML}^{\mathrm{CD} 34+}(\mathrm{CP}$ and $\mathrm{BC})$ and $\mathrm{Ph} 1 \mathrm{ALL}^{\mathrm{CD} 34+/ \mathrm{CD} 19+}$ bone marrow progenitors, $\mathrm{PP} 2 \mathrm{~A}$ activation by FTY720 resulted in marked induction of apoptosis and inhibition of cytokine-dependent clonogenic potential regardless of the expression of a wild-type or T315I BCR/ABL oncoprotein (Figures 4 and 5). Conversely, no effects were observed in primary myeloid and lymphoid bone marrow $\mathrm{CD} 34^{+}$and $\mathrm{CD} 34^{+} / \mathrm{CD} 19^{+}$progenitors from healthy individuals. In agreement with these findings, we report that activation of PP2A by forskolin and 1,9-dideoxyforskolin induces apoptosis in CML-CPCD34+, CML-BC ${ }^{\mathrm{CD} 34+}$, and imatinib-sensitive and -resistant (T315I included) cell lines but not in normal human $\mathrm{CD} 34^{+}$hematopoietic progenitors (26). Furthermore, we show that FTY720 inhibits cytokine-generated survival signals (57), suppresses Akt and Bcl-2 function, and triggers activation of proapoptotic BAD and caspase- 3 in an okadaic acid-sensitive manner (27). Similarly, PP2A-induced apoptosis is caspase dependent and involves inhibition of $\mathrm{Akt}$ and $\mathrm{Bcl}-2$ and activation of BAD $(43,66-68)$. Thus, the proapoptotic activity of FTY720 in CD34+ imatinib-sensitive and T315I CML-CP and CML-BC as well as in $\mathrm{CD}_{34} / \mathrm{CD} 19^{+} \mathrm{Ph} 1$ ALL patient cells, but not in NBM progenitors, reinforces our hypothesis that FTY720-induced cell death is a PP2A-mediated effect, at least in Ph1 cells. In addition, we show that daily administration of FTY720 for 27 weeks in SCID mice did not alter normal myelopoiesis, erythropoiesis, or thrombopoiesis, while it efficiently impaired p210 (wild-type and T315I) and p190 BCR/ABL leukemogenesis without inducing adverse effects in vivo in hematopoietic and nonhematopoietic organs. In fact, $80 \%, 50 \%$, and $90 \%$ of FTY720-treated mice injected with 32D-p210 BCR/ABL, 32D-p210 BCR/ABL (T315I), and BaF3-p190 BCR/ABL cells, respectively, were alive and with no molecular signs (BCR/ ABL negative by nested RT-PCR) of leukemia after FTY720 treatment. Notably, the use of SCID mice precluded the evaluation of the effects of FTY720 on normal lymphocyte function. However, it has been widely reported that FTY720 reversibly suppresses T and $B$ cell trafficking in rodents and humans $(31,69)$. Further- 
more, it is important to note that the FTY720 schedule and dosage were chosen based on prior reports indicating that: (a) daily (20-35 days total) administration of $10 \mathrm{mg} / \mathrm{kg}$ FTY720 severely impacts tumor cell growth without toxicity $(53-55,58,70)$; (b) longterm (100 days) daily i.p. administration of FTY720 at doses up to $10 \mathrm{mg} / \mathrm{kg}$ does not induce any histological evidence of hematopoietic or nonhematopoietic tissue damage (71), whereas doses higher than $10 \mathrm{mg} / \mathrm{kg}$ are lethal when administered to rodents for 4 to 6 months (29); and (c) the high bioavailability and long elimination half-life of FTY720 justifies its daily administration (30, 34, 72), as its blood levels remain in the nanomolar $(\sim 200 \mathrm{nM})$ range after 24-hour administration of $7.5 \mathrm{mg} / \mathrm{kg}(36)$.

In summary, because of the central role of PP2A in the regulation of cell growth, survival, and differentiation, it is clear that its loss of function is essential for the development and maintenance of CML-BC and Ph1 ALL. Moreover, the knowledge that functional inactivation of PP2A tumor suppressor activity occurs in myeloid BC CML and Ph1 ALL through the effect of p210 and p190 BCR/ $\mathrm{ABL}$ on SET expression and that pharmacologic reestablishment of normal PP2A activity antagonizes both in vitro and in vivo BCR/ $\mathrm{ABL}$ leukemogenesis, highlights the importance of incorporating PP2A-activating drugs into the current therapeutic protocols for those $\mathrm{Ph} 1$ leukemias that are nonresponsive or develop resistance to imatinib, nilotinib, and/or dasatinib. In particular, as FTY720 therapy is feasible in Phase I-III clinical trials for multiple sclerosis or solid organ transplantation, our data, for what we believe to be the first time, underscores the safety of prolonged (6.3 months) daily administration of FTY720 and strongly supports the use of this PP2A activator as a novel therapeutic approach for treatment of CML-BC and Ph1 ALL patients who are unresponsive to current kinase inhibitor therapy and, perhaps, for treatment of other cancers characterized by functional loss of PP2A activity.

\section{Methods}

Cell cultures and primary cells. The BCR/ABL-expressing 32Dcl3 and BaF3 cells, their derivative lines, and Ph1 K562 were maintained in culture in Iscove's modified Dulbecco's medium (IMDM)/10\% FBS/2 mM L-glutamine. The 32D-p210 BCR/ABL, 32D-p210 BCR/ABL (T315I), BaF3-p190 BCR/ABL, 32D-BCR/ABL-pBABE-GFP, and 32D-BCR/ABL-GFP-small-t cells were generated by retroviral infection followed by FACS-mediated sorting of the GFP-positive fraction (green fluorescent protein) or by antibiotic-mediated selection as described in ref. 73. Frozen samples of CD34+ NBM cells from different healthy donors were purchased from Cincinnati Children's Hospital. Frozen samples of mononuclear hematopoietic cells from bone marrow or PB of unidentifiable CML and Ph1 ALL patients were Ficoll separated and used either for Western blot analysis or to isolate the $\mathrm{CD} 34^{+}$and/or CD19+ fraction by using the CD34 MultiSort kit and/or CD19 microbeads (Miltenyi Biotec). The same method was used to isolate the $\mathrm{CD} 19^{+}$fraction from the normal $\mathrm{CD} 34^{+}$marrow progenitors. Before being used in different assays, $\mathrm{CD} 34^{+}$and $\mathrm{CD} 34^{+} / \mathrm{CD} 19^{+}$progenitors from healthy donors and leukemic patients were kept overnight in IMDM supplemented with 30\% FBS, $2 \mathrm{mM}$ glutamine, and human recombinant cytokines. Specifically, $\mathrm{NBM}^{\mathrm{CD} 34+}, \mathrm{CML}^{-\mathrm{CP}^{\mathrm{CD}} 34+}$ and $\mathrm{CML}-\mathrm{BC}^{\mathrm{CD} 34+}$ cells were kept in $\mathrm{IL}-3(20 \mathrm{ng} / \mathrm{ml})$, IL-6 (20 ng/ml), Flt-3 ligand (100 ng/ml), and KL (100 ng/ml) (Stem Cell Technologies Inc.), whereas $\mathrm{NBM}^{\mathrm{CD} 34+/ \mathrm{CD} 19+}$ and Ph1 $\mathrm{ALL}^{\mathrm{CD} 34+/ \mathrm{CD} 19+}$ cells were cultured in IL-7 (100 ng/ml) (Peprotech Inc.), SCF, and Flt-3 ligand, respectively. All studies were performed with human specimens obtained from The Ohio State University Leukemia Tissue Bank; the Division of Hematology, Maisonneuve-Rosemont Hospital, Division of Experimental Oncology, National Cancer Institute (Milan, Italy), and from the Depart- ment Hematology and Oncology, Oregon Health and Science University and were done with approval from The Ohio State University Institutional Review Board. Ph1 ALL patient samples were obtained in part from the Cancer and Leukemia Group B Leukemia Tissue Bank at The Ohio State University, and all patients signed Institutional Review Board-approved consent forms for the clinical sample tissue banking study CALGB 9665 and the cytogenetic study CALGB 8461. The percentage of CML-CP $\mathrm{Ph}^{+}$ cells analyzed by FISH ranged from $91 \%$ to $100 \%$. The CML-BC samples were all myeloid BC and mostly with complex karyotype, and no CML-BC samples had deletions of the der9q. Likewise, the Ph1 ALL bone marrow samples at diagnosis showed high blast counts and were mostly p190 BCR/ $\mathrm{ABL}^{+}$(2 of 12 expressed a p210 BCR/ABL oncoprotein).

Cells were treated with the following reagents used at concentrations, times, and schedules indicated in Results: imatinib mesylate (Novartis Pharmaceuticals Co.); okadaic acid and PTX (Calbiochem); 1,9-dideoxyforskolin (BioMol International); S1P (Sigma-Aldrich); and DMS, fumonisin B1, and SPHK inhibitor 2 (Cayman Chemical Company). FTY720 was synthesized with subsequent HPLC purification as described in ref. 74 . The identity and purity were confirmed by nuclear magnetic resonance and mass spectrometry. Note that, though FTY720 induces apoptosis in $\mathrm{BCR} / \mathrm{ABL}^{+}$cells at low nanomolar concentrations $\left(\mathrm{EC}_{50}=80 \mathrm{nM}\right)$, in most of the in vitro experiments we used $2.5 \mu \mathrm{M}$ because this concentration is not toxic in normal primary hematopoietic progenitors, whereas it activates $\mathrm{PP} 2 \mathrm{~A}$, induces apoptosis, and inhibits cell growth in $\mathrm{BCR} / \mathrm{ABL}^{+}$primary cells and cell lines within 6 hours of treatment. Furthermore a single $2.5 \mu \mathrm{M}$ FTY720 dose impairs the clonogenic potential of $\mathrm{Ph} 1$ leukemia but not normal progenitors.

Plasmids. The retroviral vector $\mathrm{pBABE}-\mathrm{GFP}$ and its derivative $\mathrm{pBABE}-$ GFP-sTAg carrying the SV40 small-t (Addgene plasmid 10673; provided by William C. Hahn, Dana-Farber Cancer Institute, Boston, Massachusetts, USA) have been previously described (75).

Western blot analysis. Cells $\left(1 \times 10^{7}\right)$ were lysed in $100 \mu$ of RIPA buffer (150 mM NaCl, 1\% NP40, 0.1\% SDS, 50 mM Tris [pH 8.0]) supplemented with protease and phosphatase inhibitors $(1 \mathrm{mM}$ phenylmethylsulfonylfluoride, $25 \mu \mathrm{g} / \mathrm{ml}$ aprotinin, $10 \mu \mathrm{g} / \mathrm{ml}$ leupeptin, $100 \mu \mathrm{g} / \mathrm{ml}$ pepstatin A, $5 \mathrm{mM}$ benzamidine, $1 \mathrm{mM} \mathrm{Na}_{3} \mathrm{VO}_{4}, 50 \mathrm{mM} \mathrm{NaF}, 10 \mathrm{mM} \beta$-glycerol-phosphate). After incubation on ice for 30 minutes, lysates were clarified $(12,000 \mathrm{~g}$ for 15 minutes at $4{ }^{\circ} \mathrm{C}$ ), denatured, and subjected to SDS-PAGE and Western blot as previously described (26). The antibodies used were monoclonal anti-Abl (Ab-3), anti-phosphotyrosine 4G10 (Ab-4), and anti-GRB2 (all from BD TransLab Inc.); rabbit polyclonal anti-pAkt ${ }^{\text {Thr308 }}$ and anti-Akt, mouse monoclonal anti-pERK ${ }^{\text {Thr202/Tyr204, anti-ERK, anti-pSTAT5 }}{ }^{\text {Tyr694 }}$ (Cell Signaling Technology Inc.) and anti-STAT5 (Invitrogen); and rabbit polyclonal anti-SET(I2PP2A) (Globozymes). Densitometry analysis of western blots was performed on the ImageJ software.

PP2A assays. PP2Ac assays from whole cell lysates were carried out as described in ref. 26 using the PP2Ac immunoprecipitation phosphatase assay kit (Millipore). Briefly, protein lysate $(50 \mu \mathrm{g})$ in $100 \mu \mathrm{l}$ of $20 \mathrm{mM}$ Hepes, $\mathrm{pH} 7.0 / 100 \mathrm{mM} \mathrm{NaCl}, 5 \mu \mathrm{g}$ of PP2Ac antibody (Millipore), and $25 \mu \mathrm{l}$ of Protein A-agarose were added to $400 \mu \mathrm{l}$ of $50 \mathrm{mM}$ Tris, $\mathrm{pH} 7.0 / 100 \mathrm{mM}$ $\mathrm{CaCl}_{2}$, and IPs were carried out at $4^{\circ} \mathrm{C}$ for 2 hours. IPs were washed and used in the phosphatase reaction according to the manufacturer's protocol. Specificity of the PP2A assay was assessed by titration with okadaic acid and by ascertaining the absence of PP1 $\alpha$ in the PP2A immunoprecipitates (data not shown). As an internal control, the amount of IP PP2A was also monitored by anti-PP2Ac Western blots (data not shown).

Clonogenic assays. Methylcellulose colony formation assays were carried out as previously described $(10,26,52)$. Briefly, clonogenic assays were performed by plating $10^{3}$ or $5 \times 10^{4}$ cells from BCR/ABL cell lines or primary human normal, CML, and Ph1 ALL progenitors in 0.9\% MethoCult H4230 (Stem 
Cell Technologies Inc.). Where indicated, cells were plated in the presence of recombinant mouse IL-3 (100 ng/ml), recombinant human IL-3 (100 ng/ml), or recombinant human IL-7 $(100 \mathrm{ng} / \mathrm{ml})$. Colonies $(>125 \mu \mathrm{m})$ from cell lines and primary cells were scored 7 and 15 days later, respectively.

Analysis of apoptosis and caspase activation. Apoptosis was measured using the Annexin V-FITC apoptosis detection kit (BD Biosciences - Pharmingen) according to the manufacturer's instructions. Briefly, FTY720-treated and untreated cells were Annexin V-FITC- and propidium iodide-stained for 15 minutes in $1 \times$ binding buffer (10 mM HEPES, pH 7.4, $140 \mathrm{mM}$ $\mathrm{NaCl}, 2.5 \mathrm{mM} \mathrm{CaCl}_{2}$ ) and analyzed by flow cytometry using FACSCalibur (BD Biosciences). Data were analyzed using CellQuest 3.3 software (BD Biosciences). Likewise, caspase-3/7 activities were measured on untreated and FTY720-treated cells using the caspase Glo-3/7 assay kit (Promega Corp.). Briefly, $5 \times 10^{3}$ cells were plated in a white-walled 96 -well plate, and the Z-DEVD reagent, a luminogenic caspase $3 / 7$ substrate, which contains the tetrapeptide Asp-Glu-Val-Asp, was added with a 1:1 ratio of reagent to cell solution. After 90 minutes at room temperature, the substrate cleavage by activated caspase- 3 and -7 , and the intensity of a luminescent signal was measured by a Fluoroskan Ascent FL luminometer (Thermo Electron Corp.). Differences in caspase-3/7 activity in FTY720-treated cells compared with untreated cells are expressed as fold-change in luminescence.

Nested RT-PCR. To detect $\mathrm{p} 210 \mathrm{BCR} / \mathrm{ABL}$ transcripts, RNA was extracted using the QIAamp RNA blood kit (QIAGEN) from mouse PB (100 $\mu$ l). RNA

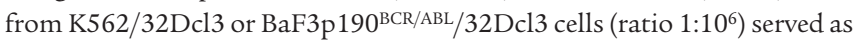
a positive control, and RNA from blood of mice not injected with BCR/ $\mathrm{ABL}^{+}$cells was used as the negative control. Total RNA $(1 \mu \mathrm{g})$ was reverse transcribed in $20 \mu \mathrm{l}$ reaction volume. cDNA $(5 \mu \mathrm{l})$ was used to detect BCR/ $\mathrm{ABL}$ transcripts by nested PCR using 2 sets of primers spanning the $\mathrm{Bcr}$ exon 12/Abl exon 3 and Bcr exon 13/Abl exon 3 under conditions previously described (76). Similarly, PCR amplification was performed to detect p190 BCR/ABL transcripts by using sets of primers spanning the Bcr exon $1 / \mathrm{Abl}$ exon 2 and the first and second steps of the PCR conditions previously described $(77,78)$. As an internal control, cDNAs $(-5 \mu \mathrm{l})$ were adjusted to yield relatively equal amplification of GAPDH.

Leukemogenesis in SCID mice. Four- to six-week-old ICR-SCID mice were i.v. injected with $5 \times 10^{5} 32 \mathrm{D}-\mathrm{p} 210^{\mathrm{BCR} / \mathrm{ABL}}$, 32D-p210 (T315I) ${ }^{\mathrm{BCR} / \mathrm{ABL}}$, or BaF3p190 BCR/ABL cells (26 mice/group). After engraftment (presence of $\mathrm{BCR} / \mathrm{ABL}^{+}$cells in PB 7 days after cell injection), cell-injected mice (13 mice/group) were i.p. treated with $10 \mathrm{mg} / \mathrm{kg} / \mathrm{d}$ of FTY720 $(250 \mu \mathrm{g} / 200 \mu \mathrm{l}$ in saline solution). Age-matched mice or mice injected with cells or drugs only (13 mice) served as controls. Four weeks after injection, 3 mice from each group were sacrificed and organs were analyzed for the presence of leukemia. At the times indicated in Figure 6A, the disease process was monitored by nested RT-PCR-mediated detection of p210 or p190 BCR/ABL transcripts using PB collected by lateral tail-vein incision. The remaining mice were used for survival studies that were terminated 24 or 27 weeks after injection. For pathological examination, tissue sections from bone marrow, spleen, liver, kidney, heart, lung, and brain were fixed in formalin, embedded in paraffin, and $\mathrm{H} \& \mathrm{E}$ stained. $\mathrm{PB}$ was collected by periorbital bleeding, depleted of rbc, cytospun onto a glass slide, and May-Grunwald/ Giemsa stained. Cytospins and tissue sections were visualized with a Zeiss Axioskope 2 Plus (original magnification, $\times 40 / 0.75$ [PB and bone marrow]; $\times 25 / 0.75$ [liver, spleen, kidney, lung, heart, and brain]). NA objectives were used. Images were taken with a Canon Powershot A70 camera and Canon RemoteCapture 2.7 software. The complete blood count was performed on a Cell Dyn 3500 Hematology Analyzer (Abbott) at the Hematology Laboratory of The Ohio State University Veterinary Teaching Hospital. All animal studies were performed with approval from The Ohio State University Institutional Laboratory Animal Care and Use Committee.

Statistics. Where indicated, data were statistically compared by using a 2-tailed Student's $t$ test and Kruskal-Wallis test. In Figure 6, the estimated probabilities for survival were calculated by the Kaplan-Meier method, and the log-rank test was used to evaluate the differences among survival distributions. A $P$ value of less than 0.01 was considered statistically significant.

\section{Acknowledgments}

This work was supported in part by National Cancer Institute grants CA095512 (to D. Perrotti), CA16058 (to The Ohio State University Comprehensive Cancer Center), and CA101140 (to M.A. Caliguri) and by grants from the US Army Chronic Myelogenous Leukemia Research Program (DAMD17-03-1-0184 and W81XWH07-1-0270; to D. Perrotti), the Leukemia Clinical Research Foundation (to C.D. Bloomfield), the Leukemia \& Lymphoma Society (to D. Perrotti, J.C. Byrd, and N. Muthusamy), the D. Warren Brown Foundation (to J.C. Byrd and N. Muthusamy), the American-Italian Cancer Foundation (to P. Neviani), the Italian Association for Cancer Research and the Italian Ministry of Health (to C. Gambacorti-Passerini), and the Fonds de la Recherche en Sante du Quebec (to D.C. Roy). We are grateful to James Van Brocklyn for helpful discussion.

Received for publication November 29, 2006, and accepted in revised form June 12, 2007.

Address correspondence to: Danilo Perrotti, The Ohio State University Comprehensive Cancer Center, 2001 Polaris Parkway, Room 205, Columbus, Ohio 43240, USA. Phone: (614) 293-5739; Fax: (614) 293-5952; E-mail: danilo.perrotti@osumc.edu.
1. Rowley, J.D. 1973. Letter: A new consistent chromosomal abnormality in chronic myelogenous leukaemia identified by quinacrine fluorescence and Giemsa staining. Nature. 243:290-293.

2. Westbrook, C.A., et al. 1992. Clinical significance of the BCR-ABL fusion gene in adult acute lymphoblastic leukemia: a Cancer and Leukemia Group B Study (8762). Blood. 80:2983-2990.

3. Melo, J.V. 1996. The diversity of BCR-ABL fusion proteins and their relationship to leukemia phenotype. Blood. 88:2375-2384.

4. Li, S., Ilaria, R.L., Jr., Million, R.P., Daley, G.Q., and Van Etten, R.A. 1999. The P190, P210, and P230 forms of the $\mathrm{BCR} / \mathrm{ABL}$ oncogene induce a similar chronic myeloid leukemia-like syndrome in mice but have different lymphoid leukemogenic activity. J. Exp. Med. 189:1399-1412.

5. Daley, G.Q., Van Etten, R.A., and Baltimore, D. 1990. Induction of chronic myelogenous leukemia in mice by the P210bcr/abl gene of the Philadelphia chromosome. Science. 247:824-830.

6. Bedi, A., Zehnbauer, B.A., Barber, J.P., Sharkis, S.J., and Jones, R.J. 1994. Inhibition of apoptosis by BCR-ABL in chronic myeloid leukemia. Blood. 83:2038-2044.

7. Savage, D.G., Szydlo, R.M., and Goldman, J.M. 1997. Clinical features at diagnosis in 430 patients with chronic myeloid leukaemia seen at a referral centre over a 16-year period. Br. J. Haematol. 96:111-116.

8. Calabretta, B., and Perrotti, D. 2004. The biology of CML blast crisis. Blood. 103:4010-4022.

9. Castor, A., et al. 2005. Distinct patterns of hematopoietic stem cell involvement in acute lymphoblastic leukemia. Nat. Med. 11:630-637.

10. Cobaleda, C., et al. 2000. A primitive hematopoietic cell is the target for the leukemic transformation in human Philadelphia-positive acute lymphoblastic leukemia. Blood. 95:1007-1013.

11. Marley, S.B., and Gordon, M.Y. 2005. Chronic myeloid leukaemia: stem cell derived but progeni- tor cell driven. Clin. Sci. (Lond.). 109:13-25.

12. Voncken, J.W., et al. 1995. BCR/ABL P210 and P190 cause distinct leukemia in transgenic mice. Blood. 86:4603-4611.

13. Faderl, S., Jeha, S., and Kantarjian, H.M. 2003. The biology and therapy of adult acute lymphoblastic leukemia. Cancer. 98:1337-1354.

14. Melo, J.V., and Deininger, M.W. 2004. Biology of chronic myelogenous leukemia - signaling pathways of initiation and transformation. Hematol. Oncol. Clin. North Am. 18:545-568, vii-viii.

15. Druker, B.J., et al. 1996. Effects of a selective inhibitor of the Abl tyrosine kinase on the growth of BcrAbl positive cells. Nat. Med. 2:561-566.

16. Deininger, M., Buchdunger, E., and Druker, B.J. 2005. The development of imatinib as a therapeutic agent for chronic myeloid leukemia. Blood. 105:2640-2653.

17. Roy, L., et al. 2006. Survival advantage from imatinib compared to the combination interferon- 
alpha plus cytarabine in chronic phase chronic myelogenous leukemia: historical comparison between two phase 3 trials. Blood. 108:1478-1484.

18. Cohen, M.H., Johnson, J.R., and Pazdur, R. 2005. U.S. Food and Drug Administration Drug Approval Summary: conversion of imatinib mesylate (STI571; Gleevec) tablets from accelerated approval to full approval. Clin. Cancer Res. 11:12-19.

19. Druker, B.J., et al. 2001. Activity of a specific inhibitor of the BCR-ABL tyrosine kinase in the blast crisis of chronic myeloid leukemia and acute lymphoblastic leukemia with the Philadelphia chromosome. N. Engl. J. Med. 344:1038-1042.

20. Ottmann, O.G., et al. 2002. A phase 2 study of imatinib in patients with relapsed or refractory Philadelphia chromosome-positive acute lymphoid leukemias. Blood. 100:1965-1971.

21. Shah, N.P., and Sawyers, C.L. 2003. Mechanisms of resistance to STI571 in Philadelphia chromosomeassociated leukemias. Oncogene. 22:7389-7395.

22. Kantarjian, H., et al. 2006. Nilotinib in imatinibresistant CML and Philadelphia chromosome-positive ALL. N. Engl. J. Med. 354:2542-2551.

23. Talpaz, M., et al. 2006. Dasatinib in imatinib-resistant Philadelphia chromosome-positive leukemias. N. Engl. J. Med. 354:2531-2541.

24. O'Hare, T., et al. 2005. In vitro activity of Bcr-Abl inhibitors AMN107 and BMS-354825 against clinically relevant imatinib-resistant $\mathrm{Abl}$ kinase domain mutants. Cancer Res. 65:4500-4505.

25. Deininger, M.W.N., et al. 2005. Comparison of imatinib, AMN107 and dasatinib in an accelerated cellbased mutagenesis screen [abstract]. Blood (ASH Annual Meeting Abstracts). 106:691.

26. Neviani, P., et al. 2005. The tumor suppressor $\mathrm{PP} 2 \mathrm{~A}$ is functionally inactivated in blast crisis CML through the inhibitory activity of the BCR/ABLregulated SET protein. Cancer Cell. 8:355-368.

27. Matsuoka, Y., Nagahara, Y., Ikekita, M., and Shinomiya, T. 2003. A novel immunosuppressive agent FTY720 induced Akt dephosphorylation in leukemia cells. Br. J. Pharmacol. 138:1303-1312.

28. Brinkmann, V. 2004. FTY720: mechanism of action and potential benefit in organ transplantation. Yonsei Med. J. 45:991-997.

29. Kahan, B.D. 2004. FTY720: from bench to bedside. Transplant Proc. 36:531S-543S.

30. Kovarik, J.M., et al. 2004. Multiple-dose FTY720: tolerability, pharmacokinetics, and lymphocyte responses in healthy subjects. J. Clin. Pharmacol. 44:532-537.

31. Chiba, K. 2005. FTY720, a new class of immunomodulator, inhibits lymphocyte egress from secondary lymphoid tissues and thymus by agonistic activity at sphingosine 1-phosphate receptors. Pharmacol. Ther. 108:308-319.

32. Dumont, F.J. 2005. Fingolimod. Mitsubishi Pharma/Novartis. IDrugs. 8:236-253.

33. Virley, D.J. 2005. Developing therapeutics for the treatment of multiple sclerosis. NeuroRx. 2:638-649.

34. Budde, K., et al. 2002. First human trial of FTY720, a novel immunomodulator, in stable renal transplant patients. J. Am. Soc. Nephrol. 13:1073-1083.

35. Skerjanec, A., et al. 2005. FTY720, a novel immunomodulator in de novo kidney transplant patients: pharmacokinetics and exposure-response relationship. J. Clin. Pharmacol. 45:1268-1278.

36. Brinkmann, V., et al. 2002. The immune modulator FTY720 targets sphingosine 1-phosphate receptors. J. Biol. Chem. 277:21453-21457.

37. Li, M., Makkinje, A., and Damuni, Z. 1996. The myeloid leukemia-associated protein SET is a potent inhibitor of protein phosphatase 2A. J. Biol. Chem. 271:11059-11062.

38. Janssens, V., and Goris, J. 2001. Protein phosphatase 2A: a highly regulated family of serine/threonine phosphatases implicated in cell growth and signalling. Biochem. J. 353:417-439.
39. Sontag, E. 2001. Protein phosphatase 2A: the Trojan Horse of cellular signaling. Cell Signal. 13:7-16.

40. Yang, S.I., et al. 1991. Control of protein phosphatase $2 \mathrm{~A}$ by simian virus 40 small-t antigen. Mol. Cell. Biol. 11:1988-1995.

41. Notari, M., et al. 2006. A MAPK/HNRPK pathway controls $\mathrm{BCR} / \mathrm{ABL}$ oncogenic potential by regulating MYC mRNA translation. Blood. 107:2507-2516.

42. Gomez, N., and Cohen, P. 1991. Dissection of the protein kinase cascade by which nerve growth factor activates MAP kinases. Nature. 353:170-173.

43. Sato, S., Fujita, N., and Tsuruo, T. 2000. Modulation of Akt kinase activity by binding to Hsp90. Proc. Natl. Acad. Sci. U. S. A. 97:10832-10837.

44. Yokoyama, N., Reich, N.C., and Miller, W.T. 2001. Involvement of protein phosphatase $2 \mathrm{~A}$ in the interleukin-3-stimulated Jak2-Stat5 signaling pathway. J. Interferon Cytokine Res. 21:369-378.

45. Saydam, G., et al. 2003. Involvement of protein phosphatase $2 \mathrm{~A}$ in interferon-alpha-2b-induced apoptosis in $\mathrm{K} 562$ human chronic myelogenous leukaemia cells. Leuk. Res. 27:709-717.

46. Windh, R.T., et al. 1999. Differential coupling of the sphingosine 1-phosphate receptors Edg-1, Edg-3, and H218/Edg-5 to the G(i), G(q), and G(12) families of heterotrimeric $\mathrm{G}$ proteins. J. Biol. Chem. 274:27351-27358.

47. Yopp, A.C., et al. 2005. Sphingosine 1-phosphate receptors regulate chemokine-driven transendothelial migration of lymph node but not splenic T cells. J. Immunol. 175:2913-2924.

48. Butler, J., Lana, D., Round, O., and LaMontagne, K. 2004. Functional characterization of sphingosine 1 phosphate receptor agonist in human endothelial cells. Prostaglandins Other Lipid Mediat. 73:29-45.

49. Tolle, M., et al. 2005. Immunomodulator FTY720 induces eNOS-dependent arterial vasodilatation via the lysophospholipid receptor S1P3. Circ. Res. 96:913-920.

50. Jendiroba, D.B., Klostergaard, J., Keyhani, A., Pagliaro, L., and Freireich, E.J. 2002. Effective cytotoxicity against human leukemias and chemotherapy-resistant leukemia cell lines by N-Ndimethylsphingosine. Leuk. Res. 26:301-310.

51. French, K.J., et al. 2003. Discovery and evaluation of inhibitors of human sphingosine kinase. Cancer Res. 63:5962-5969.

52. Uckun, F.M., et al. 1991. Interleukin 7 receptor ligation stimulates tyrosine phosphorylation, inositol phospholipid turnover, and clonal proliferation of human B-cell precursors. Proc. Natl. Acad. Sci.U. S. A. 88:3589-3593.

53. Azuma, H., et al. 2003. Induction of apoptosis in human bladder cancer cells in vitro and in vivo caused by FTY720 treatment. J. Urol. 169:2372-2377.

54. Azuma, H., et al. 2002. Marked prevention of tumor growth and metastasis by a novel immunosuppressive agent, FTY720, in mouse breast cancer models. Cancer Res. 62:1410-1419.

55. Lee, T.K., et al. 2005. FTY720: a promising agent for treatment of metastatic hepatocellular carcinoma. Clin. Cancer Res. 11:8458-8466.

56. Sonoda, Y., et al. 2001. FTY720, a novel immunosuppressive agent, induces apoptosis in human glioma cells. Biochem. Biophys. Res. Commun. 281:282-288

57. Yasui,H.,etal. 2005. FTY720 induces apoptosis in multiple myeloma cells and overcomes drug resistance. Cancer Res. 65:7478-7484.

58. Ho, J.W., et al. 2005. Effects of a novel immunomodulating agent, FTY720, on tumor growth and angiogenesis in hepatocellular carcinoma. Mol. Cancer Ther. 4:1430-1438.

59. Xin, C., Ren, S., Pfeilschifter, J., and Huwiler, A. 2004. Heterologous desensitization of the sphingosine-1-phosphate receptors by purinoceptor activation in renal mesangial cells. Br. J. Pharmacol. 143:581-589.
60. Cortez, D., Reuther, G., and Pendergast, A.M. 1997. The Bcr-Abl tyrosine kinase activates mitogenic signaling pathways and stimulates G1-to-S phase transition in hematopoietic cells. Oncogene. 15:2333-2342.

61. Zemann, B., et al. 2006. Sphingosine kinase type 2 is essential for lymphopenia induced by the immunomodulatory drug FTY720. Blood. 107:1454-1458.

62. Ogretmen, B., and Hannun, Y.A. 2004. Biologically active sphingolipids in cancer pathogenesis and treatment. Nat. Rev. Cancer. 4:604-616.

63. Suzuki, E., Handa, K., Toledo, M.S., and Hakomori, S. 2004. Sphingosine-dependent apoptosis: a unified concept based on multiple mechanisms operating in concert. Proc. Natl. Acad. Sci. U. S. A. 101:14788-14793.

64. Dobrowsky, R.T., Kamibayashi, C., Mumby, M.C., and Hannun, Y.A. 1993. Ceramide activates heterotrimeric protein phosphatase 2A. J. Biol. Chem. 268:15523-15530.

65. Wang, E., Norred, W.P., Bacon, C.W., Riley, R.T., and Merrill, A.H., Jr. 1991. Inhibition of sphingolipid biosynthesis by fumonisins. Implications for diseases associated with Fusarium moniliforme. J. Biol. Chem. 266:14486-14490.

66. Alvarado-Kristensson, M., and Andersson, T. 2005. Protein phosphatase $2 \mathrm{~A}$ regulates apoptosis in neutrophils by dephosphorylating both p38 MAPK and its substrate caspase 3. J. Biol. Chem. 280:6238-6244.

67. Moon, E.Y., and Lerner, A. 2003. PDE4 inhibitors activate a mitochondrial apoptotic pathway in chronic lymphocytic leukemia cells that is regulated by protein phosphatase 2A. Blood. 101:4122-4130.

68. Van Hoof, C., and Goris, J. 2003. Phosphatases in apoptosis: to be or not to be, PP2A is in the heart of the question. Biochim. Biophys. Acta. 1640:97-104.

69. Brinkmann, V., Cyster, J.G., and Hla, T. 2004. FTY720: sphingosine 1-phosphate receptor-1 in the control of lymphocyte egress and endothelial barrier function. Am. J. Transplant. 4:1019-1025.

70. Lee, T.K., et al. 2004. FTY720 induces apoptosis of human hepatoma cell lines through PI3-Kmediated Akt dephosphorylation. Carcinogenesis. 25:2397-2405.

71. Kim, Y.M., Sachs, T., Asavaroengchai, W., Bronson, R., and Sykes, M. 2003. Graft-versus-host disease can be separated from graft-versus-lymphoma effects by control of lymphocyte trafficking with FTY720. J. Clin. Invest. 111:659-669. doi:10.1172/ JCI200316950.

72. Kahan, B.D. 1998. FTY720: a new immunosuppressive agent with novel mechanism(s) of action. Transplant Proc. 30:2210-2213.

73. Perrotti, D., et al. 2002. BCR-ABL suppresses C/ EBPalpha expression through inhibitory action of hnRNP E2. Nat. Genet. 30:48-58.

74. Seidel, G., Laurich, D., and Furstner, A. 2004. Ironcatalyzed cross-coupling reactions. A scalable synthesis of the immunosuppressive agent FTY720. J. Org. Chem. 69:3950-3952.

75. Boehm, J.S., Hession, M.T., Bulmer, S.E., and Hahn, W.C. 2005. Transformation of human and murine fibroblasts without viral oncoproteins. Mol. Cell. Biol. 25:6464-6474.

76. Cross, N.C., et al. 1993. Competitive polymerase chain reaction to estimate the number of $\mathrm{BCR}$ ABL transcripts in chronic myeloid leukemia patients after bone marrow transplantation. Blood. 82:1929-1936.

77. Cross, N.C., Melo, J.V., Feng, L., and Goldman, J.M. 1994. An optimized multiplex polymerase chain reaction (PCR) for detection of BCR-ABL fusion mRNAs in haematological disorders. Leukemia. 8:186-189.

78. Hattori, M., et al. 1995. Detection of major and minor bcr/abl fusion gene transcripts in a patient with acute undifferentiated leukemia secondary to treatment with an alkylating agent. Leuk. Res. 19:389-396. 